Sharif University of Technology
Scientia Iranica
Transactions E: Industrial Engineering
hCIENTIA

\title{
Investigating the effect of learning on setup cost in imperfect production systems using two-way inspection plan for rework under screening constraints
}

\author{
A. Kishore, P. Gautam, A. Khanna*, and C.K. Jaggi \\ Department of Operational Research, Faculty of Mathematical Sciences, University of Delhi, Delhi-110007, India.
}

Received 4 July 2018; received in revised form 12 March 2019; accepted 28 May 2019

\author{
KEYWORDS \\ Inventory; \\ Imperfect production; \\ Two-way inspection; \\ Sales returns; \\ Learning; \\ Screening-constraints.
}

\begin{abstract}
In the industrial world of today, a growing need for the advancement and improvement of the organizations' operations is felt. Learning regarded as an inherent property is time-dependent and comes with experience. In view of this, the present study considers the process of learning for an imperfect production system in order to contribute to reducing the setup cost with the level of maturity gained, hence bringing positive results for organizations. Due to machine disturbances/malfunctions, defectives were manufactured with a known probability density function. To satisfy the demand for good products only, the manufacturer invested in a two-way inspection process with multiple screening constraints. The first inspection misclassified some of the items and delivered inaccuracies called Type-I and Type-II errors. The loss resulting from inspection at the first stage was efficiently managed through the second inspection, which was presumed to be error-free. The study mutually optimized the production backordering quantities in order to maximize the expected total profit per unit time. Numerical analysis and detailed sensitivity analysis were carried out to validate the hypothesis and further cater for some valuable implications.
\end{abstract}

(C) 2020 Sharif University of Technology. All rights reserved.

\section{Introduction and literature review}

This section showcases the inspiration behind the developed framework and presents an overview of the literature in the field of inventory management relevant to the present study. In this respect, the contribution of the present framework is established among other existing studies.

\footnotetext{
*. Corresponding author. Tel./Fax: +911127666672 E-mail addresses: kishore.aakanksha@gmail.com (A. Kishore); prerna3080@gmail.com (P. Gautam); dr.aditikhanna.or@gmail.com (A. Khanna); ckjaggi@gmail.com (C.K.Jaggi)
}

\subsection{Motivation}

Production systems prone to malfunctions have caught the attention of numerous researchers in recent years. These systems have been explored under imperfect environments in which the manufacturing process, screening process, or possibly both could be imperfect. In all cases, the results have revealed a higher percentage of defective items that are generally preferred for rework so as to become as good as new ones, while others are conventionally salvaged at a lower price without any further check for screening errors. Therefore, many papers have adopted only a singleinspection technique to separate out the defectives from the produced lot before sending them to the market even in an imperfect inspection environment. In view 
of this, a less explored area of two-way inspection plans is emphasized in this paper in which the first inspection plan is prone to errors while the second one is assumed to be error-free. The first inspection produces Type-I and Type-II errors. Due to Type-I errors, the revenue is directly affected as the non-defectives are classified as defectives. However, as a result of Type-II errors, the defectives are sold to the customers, which yield sales returns, thereby hampering the goodwill of the firm. Henceforth, through the second inspection plan, the outcome of Type-I error can be completely saved from scraping off by mistake, resulting in an increase in revenue. Moreover, the plan categorizes items into three divisions, namely perfect, reparable, and scrap items, instead of two conventional categories of reparable and non- reparable items. Such a division helps increase the number of perfect items in the inventory, which are sold at the markup price and ultimately, bring about more profit. Furthermore, learning process is an inherent property of any organization and the maturity gained through time must be considered to gain economic benefits. In lieu of this, learning with regard to production cost components is considered, which is indeed helpful in gaining profit in subsequent inventory cycles. Thus, the present paper considers a production runtime-dependent set-up cost to moderate the overall expenses of the system. In this regard, the current study fills the research gap by constructing an inventory model that deals with imperfect production systems, two-way inspection plans, inspection errors, rework, backorders, and learning in setup cost.

\subsection{Literature review}

Imperfect quality and screening errors: While investigating manufacturing systems, malfunctions should be taken into account since they are capable to produce defective items, which directly result in an economic loss for an organization. Moreover, it is necessary to manage the defectives so as to extract the monetary value of the products as much as possible. The defectives can be categorized into reworkable and non-reworkable items. The non-reworkable items can either be vended to a subordinate market at a cheap rate or be disposed of at some cost. Pioneer studies in the field of imperfect production systems were conducted by Porteus [1], Rosenblatt and Lee [2], Lee and Rosenblatt [3], Kim and Hong [4], BenDaya and Hariga [5], Salameh and Jaber [6], Cardenas Barron [7], Huang [8], Chung and Hou [9], Yeh et al. [10], Ben-Daya and Rahim [11], Huang [12], Hsieh and Lee [13], Chen and Lo [14], and Wee et al. [15]. While dealing with items of imperfect quality, it is necessary to adopt screening process that may include some human errors. Therefore, it is reasonable to incorporate screening errors into the inventory model in order to make it closer to the real-time manufacturing process. Raouf et al. [16] as the pioneer contributors to the field of inspection incorporated the effect of human error into their model. Later, Duffuaa and Khan [17] and Duffuaa and Khan [18] extended the work to study misclassification of the good items into bad ones and vice versa. Furthermore, Zhou et al. [19], Al-Salamah [20], Khan et al. [21], Khanna et al. [22], Pal and Mahapatra [23], and Sett et al. [24] recently explored the area of inspection errors with other realistic scenarios for inventory management.

Imperfect quality and rework: To compensate for the failure of increasing the profit margins mainly due to misclassifications and the consequent sale and salvage of defectives, implementing the rework process apart from planning the backorders is found useful. In addition, shortages are likely to occur whenever there is a supply or demand difficulty, especially under an imperfect quality environment. Hayek and Salameh [25] looked into the significance of rework when there were defective items in the inventory system of finite production model with shortages. In several production systems, imperfect items are preferred for rework and significantly reduce the total costs of production and inventory. Several significant contributions made in this field are those of Chiu [26], Chiu et al. [27], Chiu et al. [28], Chiu et al. [29], Sana [30], Sarkar et al. [31,32], and Dey and Giri [33]. Later, Chiu [34], Lin [35], and Yoo et al. [36] explored the area of inventory modeling with imperfect items, screening process, and rework. Recently, Hsu and Hsu [37] and Wee et al. [38] developed an optimal replenishment model with defective items, screening errors, shortages, and sales returns. Cárdenas-Barrón et al. [39] put forth a pioneering work through a brief introduction to the inventory papers. Taleizadeh et al. [40] proposed an optimal order quantity model with partial backorders and reparation of imperfect products. Wang et al. [41] also proposed an optimal order quantity model, taking into account the screening constraints. Jaggi et al. [42], Moussawi-Haidar et al. [43], Liao [44], Pal et al. [45], Shah et al. [46], Sekar and Uthayakumar [47], Benkherouf et al. [48], Chen [49], Shafiee-Gol et al. [50], Jawla and Singh [51], Cárdenas-Barrón et al. [52], Nobil et al. [53], Chung et al. [54], and Nobil et al. [55] have recently explored the area of inventory management by employing various rework scenarios.

Learning in setup cost: Learning is a timedependent process that comes into picture when the maturity phase of an organization and its workers is fulfilled. In particular, learning in setup cost is a dynamic process through which setup costs can be reduced with the onset of learning in the subsequent cycles. This process was previously adopted by Adler and Nanda [56], Sule [57], and Urban [58]. The effect 
Table 1. Comparison of contributions of different authors.

\begin{tabular}{|c|c|c|c|c|c|c|}
\hline Research papers & $\begin{array}{c}\text { Imperfect } \\
\text { quality }\end{array}$ & $\begin{array}{c}\text { Inspection } \\
\text { errors }\end{array}$ & $\begin{array}{l}\text { Screening } \\
\text { constraints }\end{array}$ & $\begin{array}{c}\text { Sales } \\
\text { returns }\end{array}$ & Rework & $\begin{array}{c}\text { Learning in } \\
\text { setup cost }\end{array}$ \\
\hline Duffuaa and Khan [18] & Yes & Yes & No & No & No & No \\
\hline Khan et al. [21] & Yes & Yes & No & No & Yes & Yes \\
\hline Khanna et al. [22] & Yes & Yes & No & Yes & Yes & No \\
\hline Jaggi et al. [42] & Yes & Yes & No & Yes & Yes & No \\
\hline Shafiee-Gol [50] & Yes & No & No & No & Yes & No \\
\hline Jawla and Singh [51] & Yes & No & No & No & Yes & No \\
\hline Cárdenas-Barrón et al. [52] & Yes & No & No & No & Yes & No \\
\hline Nobil et al. [53] & Yes & No & No & No & Yes & No \\
\hline Chung et al. [54] & Yes & No & No & No & Yes & No \\
\hline Nobil et al. [55] & Yes & Yes & No & No & Yes & No \\
\hline Konstantaras et al. [64] & Yes & No & No & No & No & No \\
\hline Mukhopadhyay and Goswami [65] & Yes & No & No & No & No & Yes \\
\hline Gautam and Khanna [66] & Yes & No & No & Yes & No & No \\
\hline Present paper & Yes & Yes & Yes & Yes & Yes & Yes \\
\hline
\end{tabular}

of learning and forgetting was incorporated in many papers thereafter. Jaber and Bonney [59] presented an extended review of learning in their study. Later, other researchers including Jaber and Bonney [60], Jaber [61], and Darwish [62] investigated the process of learning in their inventory modeling. Khan et al. [63] presented an inventory model with defective items and learning inspection. Konstantaras [64] extended the model of Khan et al. [63] by incorporating shortages. Recently, Mukhopadhyay and Goswami [65] proposed an imperfect production inventory model for three kinds of defectives with rework and learning setup. Table 1 gives a quick review of the literature and filled research gaps.

Our contribution: Inventory management revolves around products and customers. The process of managing products is categorized into numerous parts, implementing all required activities such as manufacturing, screening, rework, and sales refunds when the end consumer is not satisfied. Therefore, it makes sense to employ product management, i.e., controlling the perfect and imperfect products for realistic inventory modeling. In order to efficiently manage the whole lot, first, an "error-prone" screening process is employed on the complete batch that discards some perfect products by mistake (an outcome of Type-I error) and erroneously sells some defectives as perfect items (an outcome of Type-II error). In order to reduce the loss resulting from compromised screening at first hand, another screening process is simultaneously run in the smaller lot of accumulated defectives (consisting of both actual and wrongly-classified defectives) under rigorous surveillance at a relatively higher cost than the first inspection process. Since this re-inspection is conducted with higher quality, it seems to be errorfree and successfully nullifies the loss resulting from Type-I error by completely extracting the perfect items (that are wrongly classified as defectives). Finally, this second inspection successfully categorizes the accumulated defectives into three parts, namely perfect, reparable, and non-reparable. Thus, it contributes to increasing the number of perfect items and hence, the revenue from an additional investment in the second inspection process. After these two simultaneous screening processes, the rework process begins on the reparable lot, which adds up to the revenue at a marginal cost of rework. Therefore, contrary to the previous research practices that considered the single and perfect inspection capable to handle the defectives, the present paper investigates the imperfect production systems under the condition of two-way inspection processes with screening errors at the first stage only along with sales returns. Therefore, a rework process is employed for accumulated defectives under various screening constraints for achieving higher standards of quality and revenue as well. Additionally, learning in setup cost is considered in this model to gain some maturity with time and elevate the profit values. Two mathematical models are proposed for imperfect production system with and without considering the effects of learning. Numerical and sensitivity analyses are carried out to showcase the key features. Furthermore, the importance of two-way inspection plan is signified through a comparative study. The model is applicable to a variety of manufacturing industries that target high standards of quality and customer satisfaction, encourage teamwork, and prefer to invest in learning. 


\section{Model development}

The present segment gives the notation, assumptions, and constraints based on which the model is developed.

\subsection{Notation}

Parameters

$\Lambda$

$\Phi$

$\varphi_{1}$

$x$

$\alpha$

$q_{1}$

$q_{2}$

$p_{1}$

\section{$T$}

$E($.

$E(\theta)$

$K_{0}$

$c_{P}$

$i_{1}$

$i_{2}$
Demand rate of units per unit time

Production rate

Rework rate

Inspection rate in units per unit time, $\lambda>D$

Proportion of imperfect items (a random variable with known p.d.f.)

Proportion of Type-I imperfection error (a random variable with known p.d.f.)

Proportion of Type-II imperfection error (a random variable with known p.d.f.)

\section{Proportion of non-reparable/scrap} items (a random variable with known p.d.f.)

Proportion of reparable items (a random variable with known p.d.f.)

Proportion of perfect items, secluded from the second inspection process (a random variable with known p.d.f.)

Proportion of rework items (a random variable with known p.d.f.)

Cycle length

\section{Expected value operator}

Expected value of $\theta$

Production setup cost for each cycle

$$
\text { Purchase cost per item (\$/item) }
$$

Inspection cost per item during production $(\$ /$ item $)$

$i_{2}$ Inspection cost per item after production $(\$ /$ item $)$

\section{Selling price $(\$ /$ item $)$}

Disposal cost of defectives $(<s)$ $(\$ /$ item $)$

Unit discounted price of each defective item $(<s)(\$ /$ item $)$

\section{Shortage cost per unit per unit time}

$c_{r} \quad$ Cost of obligating Type-I error $(\$ /$ item $)$

$c_{a} \quad$ Cost of obligating Type-II error $(\$ /$ item $)$

Holding cost per unit time $h_{1} \quad$ Holding cost of reworked items per unit time

Decision variables

$y \quad$ Production lot size

$B \quad$ Backorder level

Functions

$f(\alpha) \quad$ p.d.f. of defective items

$f\left(q_{1}\right) \quad$ p.d.f. of Type-I error

$f\left(q_{2}\right) \quad$ p.d.f. of Type-II error

$f(r) \quad$ p.d.f. of rework items

$f\left(p_{1}\right) \quad$ p.d.f. of scrap items

$f\left(p_{2}\right) \quad$ p.d.f. of non-repairable items

$f\left(p_{3}\right) \quad$ p.d.f. of repairable items

T.C. Total cost

E.T.C.U. Expected total cost per unit time

T.R. Total revenue

E.T.R.U. Expected total revenue per unit time

$Z_{j}(y, B) \quad$ Total profit per unit time for $j=1,2$

$E\left[Z_{j}(y, B)\right]$ Expected total profit per unit time for $j=1,2$

Optimal values

$T^{*} \quad$ Optimal cycle length

$y^{*} \quad$ Optimal order quantity per cycle

$B^{*} \quad$ Optimal backorder level

$E\left[Z^{*}(y, B)\right]$ Optimal expected total profit per unit time

\subsection{Assumptions}

The mathematical model is proposed based on the following assumptions:

1. Demand rate is constant, uniform, and deterministic. Moreover, demand is satisfied by perfect items only;

2. Production rate is finite and constant;

3. Production process produces only single-product type and delivers some imperfect items as well;

4. Screening process first leads to Type-I and Type-II misclassification errors;

5. The second procedure of inspection is error-free and produces three types of items, namely perfect, repairable, and non-repairable;

6. Rework process is run after the end of the second inspection procedure;

7. The screening cost during production is higher than that for production completion;

8. The holding cost of defectives that are reworked is more than that of non-defective items; 
9. The manufacturer who learns from the past experiences is able to eventually reduce the setup time and cost;

10. The non-learning model can be the trivial case of the present study, i.e., $\epsilon=0$;

11. Shortages are allowed and fully backlogged;

12. Time period is infinite and lead time is insignificant.

\subsection{Model constraints}

1. Production rate is greater than screening rate $(\phi>$ $x)$;

2. Screening rate is greater than demand rate $(x>\lambda)$;

3. Rework rate is greater than demand rate $(\phi>\lambda)$;

4. Since some perfect items will always be there in the inventory, $1-E\left[p_{1}\right]>0$;

5. In order to eliminate the backorders and maintain the positive inventory, consider $\left(1-E\left[p_{1}\right]\right) x-\lambda>$ 0 ;

6. In order to avoid shortages during the screening process, the number of inspected perfect items should be at least equal to the demand rate during that specific period, i.e. $\frac{\lambda y}{x} \leq y\left(1-E\left[p_{1}\right]\right)$;

7. Production rate of perfect items satisfies the inequality $\phi\left(1-E\left[p_{1}\right]\right)>x$.

\subsection{Screening constraints}

1. When the production rate is greater than the screening time, the screening process will continue even after the production process, i.e. $\left(t_{4}>0\right)$;

2. For smooth functioning of inventory, screening should be finalized before the completion of inventory, i.e. $t_{4}<\left(t_{5}+t_{6}\right)$;

3. The total expected cost of production and screening should be less than the total sales revenue earned by selling both perfect and imperfect items, i.e. $c_{p}+$ $d_{1}+d_{2}<s(1-\alpha)-s \alpha q_{2}+s \alpha r+v \alpha(1-r)$.

\section{Mathematical modeling}

The present section presents the problem definition so as to give a clear picture of the problem under study and formulate the mathematical model that fits the abovementioned assumptions and constraints.

\subsection{Problem definition}

Manufacturing systems are loaded with a number of sub-units and due to factors such as interrupted supply of power, age-based issues, malfunction of tools, overheating of the machines, etc. a system may finally stop producing defectives. The defective items should be removed from the lot through a vigilant screening process. However, the screening is not always errorfree due to a number of factors such as lack of enough work instructions, human error, weak control over the entire screening process, etc. that finally lead to misclassification of both Type-I and Type-II errors. The first type of error results in a direct loss of revenue for the manufacturer and as a result of the second type of error, the defective items are delivered to the customers who bring sales returns. To reduce the damage brought about by the goodwill of the manufacturer in the market, sales returns are also legitimate for full price refunds. To effectively manage the whole inventory system, the management of all items that are actually defective, wrongly-classified as defective or even returned by customers, is vital. As a result of Type-I error, another inspection process is needed that is capable of not only saving the perfect items from getting scrapped at a reduced price or getting them reworked for no use, but also extracting them successfully at a marginal cost of the second inspection process only. To this end, the second inspection process is considered to be error-free, thus providing the manufacturer with three types of products including non-reparable $\left(p_{1}=\alpha(1-r)\right)$, reparable $\left(p_{2}=\alpha r\right)$, and perfect $\left(p_{3}=(1-\alpha) q_{1}\right)$ that are particularly victimized by the Type-I error earlier. Furthermore, a rework process is employed in order to transform the items of reparable category into perfect ones at some rework cost. Moreover, the process of learning is an ongoing time-dependent process and learning in the setup of the production process is of great importance for the manufacturer. With time, the organization is able to learn well, which should be incorporated into the subsequent production cycles in order to increase the efficiency of the firm. In light of this, the present study develops two cases for an inventory model with and without the effects of learning in setup cost with defectives, two-stage inspection process, screening errors in the first inspection procedure, perfect rework process, disposal of non-reparable stock, and incorporation of fully backlogged shortages. The proposed model was explored under several realistic model and screening constraints in order to obtain more practical results. The sequential flow of the abovementioned events is given in Figure 1.

The manufacturer's problem is formulated by jointly optimizing both optimal production batch size and backorder size. Profit is obtained by subtracting all cost components including costs of production, inspection, misclassification, rework, shortage, disposal, and holding from the revenue, which is obtained by the sales of good, imperfect, and reworked items. Furthermore, the fractions of Type-I and Type-II errors are considered independent of defect proportion.

\subsection{Mathematical formulation}

The present fragment formulates a mathematical model which fits the problem description and assumptions. 


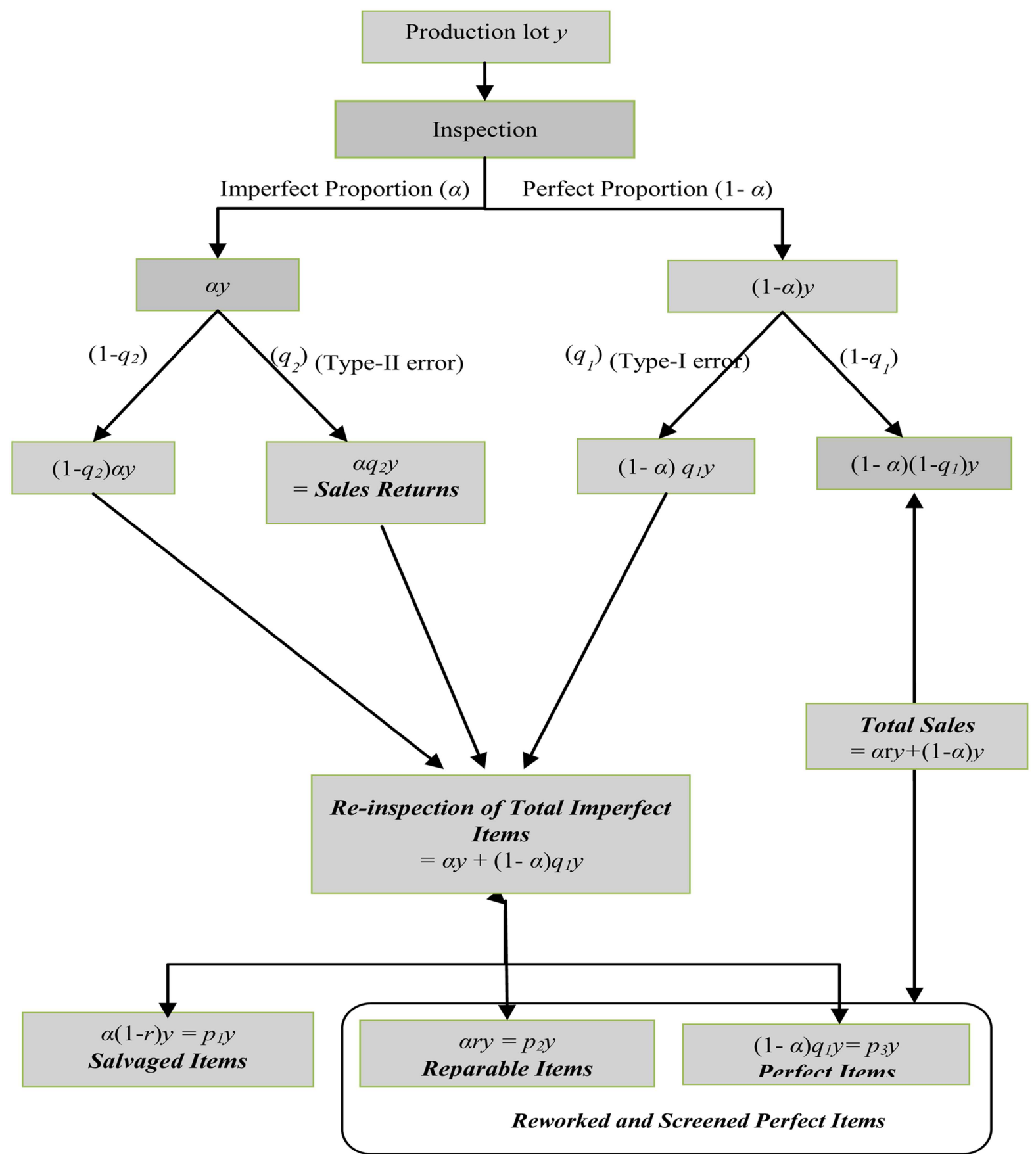

Figure 1. Sequence of events in the inventory cycle.

The graphical representation of the inventory is given in Figure 2.

The total outcome of the perfect items sorted after the combined effects of inspection and rework processes is $\left(l-p_{1}\right) y$ where $p_{1}$ is expanded in Appendix A.

Since demand is satisfied through only perfect items, the length of the total cycle is defined as the total number of sold perfect items per demand rate, i.e.:

$$
T=\left(1-p_{1}\right) \frac{y}{\lambda}
$$

Shortages are there from the beginning of the inventory cycle, i.e., from time 0 to $A_{1}$. Therefore, the total backorder building time is calculated as:

$$
t_{1}=\frac{B}{\lambda}
$$

After time point $A_{1}$, shortages begin to decrease and get completely eliminated by $A_{2}$. Therefore, complete shortage elimination time is determined by:

$$
t_{2}=\frac{B}{\left(1-p_{1}\right) x-\lambda} \text {. }
$$




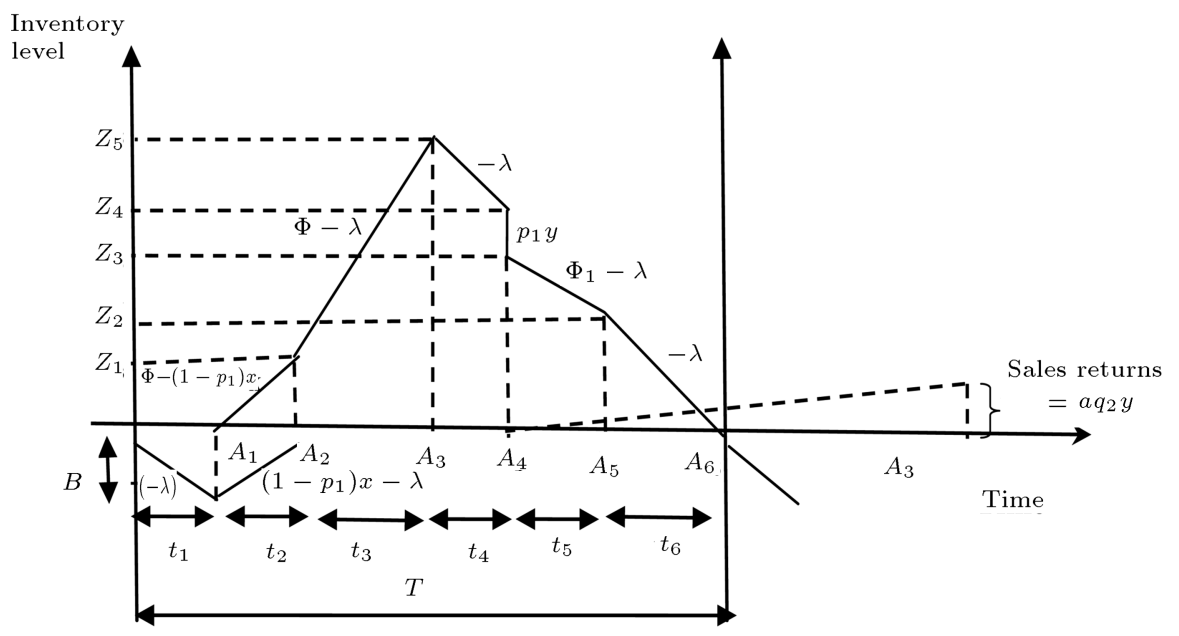

Figure 2. Inventory behavior of the system.

Furthermore, the whole inventory of defectives built during the shortage removal time $\left(A_{1}, A_{2}\right)$ is estimated as:

$$
z_{1}=\left[\phi-\left(1-p_{1}\right) x\right] t_{2}=\frac{\left[\phi-\left(1-p_{1}\right) x\right] B}{\left(1-p_{1}\right) x-\lambda} .
$$

The overall inventory during time period $\left(A_{2}, A_{3}\right)$ is constructed by the accumulation of defectives and unsold perfect items. The uptime of this inventory is calculated as:

$$
t_{3}=\frac{z_{5}-z_{1}}{\phi-\lambda}=\frac{1}{\phi-\lambda}\left\{z_{5}-\frac{\left[\phi-\left(1-p_{1}\right) x\right] B}{\left(1-p_{1}\right) x-\lambda}\right\}
$$

Moreover, the entire production runs within a period of $A_{1}$ up to $A_{3}$ and duration of the period can be obtained by adding lengths $t_{2}, t_{3}$, i.e.:

$$
t_{2}+t_{3}=\frac{y}{\phi} \text {. }
$$

By substituting the value of Eq. (3) into the above equation:

$$
t_{3}=\frac{y}{\phi}-\frac{B}{\left(1-p_{1}\right) x-\lambda} .
$$

By equating Eqs. (5) and (7), the value of $z_{5}$ is obtained as:

$$
\begin{aligned}
z_{5}= & \frac{\left[\phi-\left(1-p_{1}\right) x\right] B}{\left(1-p_{1}\right) x-\lambda} \\
& +(\phi-\lambda)\left[\frac{y}{\phi}-\frac{B}{\left(1-p_{1}\right) x-\lambda}\right] .
\end{aligned}
$$

Since the total screening time is presumed to exceed the production time, it varies from time point $A_{1}$ to $A_{4}$ given by:

$$
t_{2}+t_{3}+t_{4}=\frac{y}{x} .
$$

By substituting the value of Eq. (6) into the above equation:

$$
t_{4}=\frac{y}{x}-\frac{y}{\phi} .
$$

Furthermore, the total inventory depleted during the post-production screening time is determined as:

$$
z_{5}-z_{4}=\lambda t_{4}
$$

Through Eqs. (8), (10), and (11), the value of $z_{4}$ is obtained as:

$$
\begin{aligned}
z_{4}= & \frac{\left[\phi-\left(1-p_{1}\right) x\right] B}{\left(1-p_{1}\right) x-\lambda} \\
& +(\phi-\lambda)\left[\frac{y}{\phi}-\frac{B}{\left(1-p_{1}\right) x-\lambda}\right] \\
& -\lambda\left(\frac{y}{x}-\frac{y}{\phi}\right) .
\end{aligned}
$$

The defectives which are to be scrapped add up to $p_{1} y$ and are disposed right after the end of the screening process, i.e., at $A_{4}$. Therefore, the effective inventory is instantaneously reduced and obtained by:

$$
\begin{aligned}
z_{3}= & z_{4}-p_{1} y=\frac{\left[\phi-\left(1-p_{1}\right) x\right] B}{\left(1-p_{1}\right) x-\lambda} \\
& +(\phi-\lambda)\left[\frac{y}{\phi}-\frac{B}{\left(1-p_{1}\right) x-\lambda}\right] \\
& -\lambda\left(\frac{y}{x}-\frac{y}{\phi}\right)-p_{1} y .
\end{aligned}
$$

Next, the rework process of a fraction from total accumulated defectives starts right after the second inspection procedure. The second inspection is done hand over hand and its time period is not taken into account. Therefore, the rework runtime, which begins from $A_{4}$ and continues until $A_{5}$, is determined as: 


$$
\begin{aligned}
t_{5}= & \frac{z_{3}-z_{2}}{\phi_{1}-\lambda}=\frac{1}{\phi_{1}-\lambda}\left\{\frac{\left[\phi-\left(1-p_{1}\right) x\right] B}{\left(1-p_{1}\right) x-\lambda}\right. \\
& +(\phi-\lambda)\left[\frac{y}{\phi}-\frac{B}{\left(1-p_{1}\right) x-\lambda}\right] \\
& \left.-\lambda\left(\frac{y}{x}-\frac{y}{\phi}\right)-p_{1} y-z_{2}\right\} .
\end{aligned}
$$

In addition, out of the entire defective inventory $\alpha y$, the count of reworkable is $p_{2} y$ and the rework processing time is rewritten as:

$$
t_{5}=\frac{p_{2} y}{\phi_{1}}
$$

By equating Eqs. (14) and (15), the value of $z_{2}$ is obtained as:

$$
\begin{aligned}
z_{2}= & \frac{\left[\phi-\left(1-p_{1}\right) x\right] B}{\left(1-p_{1}\right) x-\lambda} \\
& +(\phi-\lambda)\left[\frac{y}{\phi}-\frac{B}{\left(1-p_{1}\right) x-\lambda}\right] \\
& -\lambda\left(\frac{y}{x}-\frac{y}{\phi}\right)-p_{1} y-\frac{p_{2} y\left(\phi_{1}-\lambda\right)}{\phi_{1}} .
\end{aligned}
$$

Finally, the remaining perfect items obtained from the rework process $\left(p_{2} y\right)$ and those directly segregated from the second inspection process $\left(p_{3} y\right)$ are sold until the inventory completely depletes to zero. Thus:

$$
\begin{aligned}
t_{6}= & \frac{z_{2}}{\lambda}=\frac{1}{\lambda}\left\{\frac{\left[\phi-\left(1-p_{1}\right) x\right] B}{\left(1-p_{1}\right) x-\lambda}\right. \\
& +(\phi-\lambda)\left[\frac{y}{\phi}-\frac{B}{\left(1-p_{1}\right) x-\lambda}\right] \\
& \left.-\lambda\left(\frac{y}{x}-\frac{y}{\phi}\right)-p_{1} y-\frac{p_{2} y\left(\phi_{1}-\lambda\right)}{\phi_{1}}\right\} .
\end{aligned}
$$

The whole screening process is covered in two parts, one ends with the production procedure and runs for a length of $\left(t_{2}+t_{3}\right)$ and the other begins after completion of the production process and runs for a length of $\left(t_{4}\right)$, i.e. until all the remaining items are screened. In this regard, the number of units screened during the first interval $\left(A_{1}, A_{3}\right)$ is obtained through:

$$
\begin{aligned}
& =\left[\lambda+\lambda \alpha+\lambda \alpha^{2}+\ldots .\right]\left(t_{2}+t_{3}\right)=\frac{\lambda\left(t_{2}+t_{3}\right)}{1-\alpha} \\
& =\frac{\lambda y}{\phi(1-\alpha)} . \\
& =A y, \text { where } A=\frac{\lambda}{\phi(1-\alpha)} .
\end{aligned}
$$

To estimate the total number of units screened during the second interval $\left(A_{3}, A_{4}\right)$, the final number of defectives accumulated by time point $A_{3}$ is determined and then, subtracted from the maximum inventory level present in that specific time period $z_{5}$. The total number of defectives accumulated during $\left(A_{3}, A_{4}\right)$ is obtained by the total units screened by time point $A_{3}$ minus the demand satisfied in this time, i.e.:

$$
=A y-\lambda t_{1} \text {. }
$$

Using Eq. (20), the total number of items screened between $\left(A_{3}, A_{4}\right)$ is calculated:

$$
\begin{aligned}
= & z_{5}-\left(A y-\lambda t_{1}\right) . \\
= & \frac{\left[\phi-\left(1-p_{1}\right) x\right] B}{\left(1-p_{1}\right) x-\lambda}+(\phi-\lambda)\left[\frac{y}{\phi}-\frac{B}{\left(1-p_{1}\right) x-\lambda}\right] \\
& -\frac{\lambda y}{\phi(1-\alpha)}-B .
\end{aligned}
$$

Furthermore, this model incorporates the effect of learning in setup cost by assuming a variable setup cost function depending on the production run length $T_{P}$, where:

$$
\begin{aligned}
& T_{P}=t_{2}+t_{3}, \\
& C_{0}\left(T_{P}\right)= \begin{cases}C_{0}\left(\mathrm{~T}_{P}\right) & \mathrm{T}_{P}<T_{M} \\
C_{\max } & \mathrm{T}_{P} \geq T_{M}\end{cases} \\
& C_{0}\left(T_{P}\right)= \begin{cases}C_{0}\left(\frac{y}{\phi}\right) & \mathrm{T}_{P}<T_{M} \\
C_{\max } & \mathrm{T}_{P} \geq T_{M}\end{cases}
\end{aligned}
$$

where $\in$ is the shape factor, $C_{0}$ is the setup cost related to the basic production quantity model when the shape factor is zero, and $T_{M}$ is the minimum run length after which the setup process requires the maximum cost $\left(C_{\max }\right)$.

The cost $\left(C_{\max }\right)$ acts as an upper limit for the setup cost. The shape factor $\in$ is estimated using the past data for earlier manufacturing practices and adopting the curve fitting method. Darwish [53] represented the setup cost against the production run length for different values of shape factor $(\epsilon)$ as demonstrated in Figure 3.

\subsection{Components of sales revenue}

The components of revenue are evaluated as follows:

$R_{1} \quad$ Sales of only good quality items

$$
=s(1-\alpha)\left(1-q_{1}\right) y+s \alpha q_{2} y,
$$

$R_{2} \quad$ Loss of revenue from sales returns

$$
=-s \alpha q_{2} y,
$$

$R_{3} \quad$ Sales of reworked items

$$
=s \alpha r y,
$$




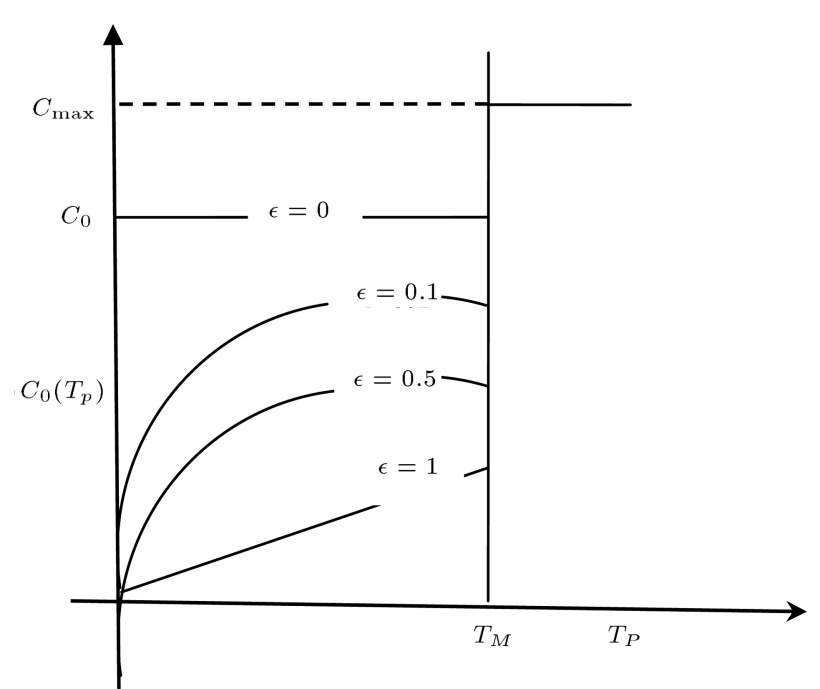

Figure 3. Behavior of setup cost.

$R_{4} \quad$ Sales of misclassified perfect items

$$
\text { (outcome of Type-I error) }=s(1-\alpha) q_{1} y,
$$

$R_{5} \quad$ Sales of scrap/non-reworkable items

$$
=v \alpha(1-r) y \text {. }
$$

By adding the sales of items with high quality, revenue loss in sales returns, sales from reworked items, sales of scrap items, and sales of non-reworkable items, the total revenue of the manufacturer is obtained as follows:

$$
\begin{aligned}
T . R . & =R_{1}+R_{2}+R_{3}+R_{4}+R_{5}=s(1-\alpha) y \\
& +s \alpha r y+v \alpha(1-r) y .
\end{aligned}
$$

\subsection{Components of inventory system costs}

The cost components that are incurred in the present inventory scenario are:

- Setup cost obtained from introducing the effects of learning into setup costs:

$$
C_{0}\left(T_{P}\right)= \begin{cases}C_{0}\left(\frac{y}{\phi}\right)^{\in} & \mathrm{T}_{P}<T_{M} \\ C_{\max } & \mathrm{T}_{P} \geq T_{M}\end{cases}
$$

- Purchase cost including the variable cost per cycle:

$$
C_{p} y .
$$

- Screening cost of the first inspection process during production runtime:

$$
d_{1}\left(\frac{\lambda y}{\phi(1-\alpha)}\right) \text {. }
$$

- Screening cost of the first post-production inspection process:

$$
\begin{aligned}
& d_{2}\left\{\frac{\left[\phi-\left(1-p_{1}\right) x\right] B}{\left(1-p_{1}\right) x-\lambda}+(\phi-\lambda)\right. \\
& {\left.\left[\frac{y}{\phi}-\frac{B}{\left(1-p_{1}\right) x-\lambda}\right]-\frac{\lambda y}{\phi(1-\alpha)}-B\right\} . }
\end{aligned}
$$

- Screening cost of the second inspection process:

$$
d_{3}\left[\alpha y+(1-\alpha) q_{1} y\right] .
$$

- Rework cost:

$$
C_{w} \alpha r y \text {. }
$$

- The incurred cost of Type-I error due to the inspector's misclassification of some fractions of nondefectives as defectives:

$$
C_{r}(1-\alpha) q_{1} y \text {. }
$$

- The incurred cost of Type-II error due to the inspector's misclassification of a portion of defectives as non-defectives:

$$
\mathrm{C}_{a} \alpha q_{2} y \text {. }
$$

- Disposal cost of non-reworkable items:

$$
u \alpha(1-r) y \text {. }
$$

- Holding cost of the defectives, non-defectives, and sales returns in a cycle:

$$
\begin{aligned}
h\left[\frac{1}{2} z_{1} t_{2}+\frac{1}{2} t_{3}\left(z_{1}+z_{5}\right)\right. & +\frac{1}{2} t_{4}\left(z_{5}+z_{3}\right) \\
+ & \left.\frac{1}{2} t_{6} z_{2}+\frac{1}{2} \alpha q_{2} y T\right]+h_{1} \frac{1}{2}\left(z_{3}+z_{2}\right) t_{5} .
\end{aligned}
$$

- Shortage cost:

$$
C_{B} \frac{1}{2}\left(t_{1}+t_{2}\right) B
$$

Since the present model is developed under the assumption of learning in setup cost, two cases are established for the manufacturer's total cost depending upon the learning effects:

Case I: $\boldsymbol{T}_{\boldsymbol{P}}<\boldsymbol{T}_{\boldsymbol{M}}$ (under the effects of learning) When $T_{P}<T_{M}$, the following value is obtained for the total cost of the manufacturer by substituting the appropriate value of $C_{0}\left(T_{P}\right)$ :

$$
\begin{aligned}
\text { T.C.1 } & =C_{0}\left(\frac{y}{\phi}\right)^{\in}+C_{p} y+d_{1}\left(\frac{\lambda y}{\phi(1-\alpha)}\right) \\
& +d_{2}\left\{\frac{\left[\phi-\left(1-p_{1}\right) x\right] B}{\left(1-p_{1}\right) x-\lambda}+(\phi-\lambda)\right. \\
& {\left.\left[\frac{y}{\phi}-\frac{B}{\left(1-p_{1}\right) x-\lambda}\right]-\frac{\lambda y}{\phi(1-\alpha)}-B\right\} } \\
& +d_{3}\left[\alpha y+(1-\alpha) q_{1} y\right]+C_{w} \alpha r y \\
& +C_{r}(1-\alpha) q_{1} y+C_{a} \alpha q_{2} y+u \alpha(1-r) y
\end{aligned}
$$




$$
\begin{aligned}
& +h\left[\begin{array}{c}
\frac{1}{2} z_{1} t_{2}+\frac{1}{2} t_{3}\left(z_{1}+z_{5}\right)+\frac{1}{2} t_{4}\left(z_{5}+z_{3}\right) \\
+\frac{1}{2} t_{6} z_{2}+\frac{1}{2} \alpha q_{2} y T
\end{array}\right] \\
& +h_{1} \frac{1}{2}\left(z_{3}+z_{2}\right) t_{5}+C_{B} \frac{1}{2}\left(t_{1}+t_{2}\right) B .
\end{aligned}
$$

The manufacturer's total profit for Case I is shown in the following:

$$
\begin{aligned}
& \text { T.P.1. }=s(1-\alpha) y+s \alpha r y+v \alpha(1-r) y \\
& -C_{0}\left(\frac{y}{\phi}\right)^{\epsilon}-C_{p} y-d_{1}\left(\frac{\lambda y}{\phi(1-\alpha)}\right) \\
& -d_{2}\left\{\frac{\left[\phi-\left(1-p_{1}\right) x\right] B}{\left(1-p_{1}\right) x-\lambda}+(\phi-\lambda)\right. \\
& \left.\left[\frac{y}{\phi}-\frac{B}{\left(1-p_{1}\right) x-\lambda}\right]-\frac{\lambda y}{\phi(1-\alpha)}-B\right\} \\
& -d_{3}\left[\alpha y+(1-\alpha) q_{1} y\right]-C_{w} \alpha r y \\
& -C_{r}(1-\alpha) q_{1} y-C_{a} \alpha q_{2} y-u \alpha(1-r) y \\
& -\frac{h}{2} \frac{\left[\phi-\left(1-p_{1}\right) x\right] B^{2}}{\left[\left(1-p_{1}\right) x-\lambda\right]^{2}} \\
& -h\left[\frac{y}{\phi}-\frac{B}{\left(1-p_{1}\right) x-\lambda}\right]\left[\frac{\left[\phi-\left(1-p_{1}\right) x\right] B}{\left(1-p_{1}\right) x-\lambda}\right] \\
& -\frac{h}{2}(\phi-\lambda)\left[\frac{y}{\phi}-\frac{B}{\left(1-p_{1}\right) x-\lambda}\right]^{2} \\
& -\frac{h}{2}\left(\frac{y}{x}-\frac{y}{\phi}\right)\left\{\frac{2\left[\phi-\left(1-p_{1}\right) x\right] B}{\left(1-p_{1}\right) x-\lambda}\right. \\
& +2(\phi-\lambda)\left[\frac{y}{\phi}-\frac{B}{\left(1-p_{1}\right) x-\lambda}\right] \\
& \left.-\lambda\left(\frac{y}{x}-\frac{y}{\phi}\right)-p_{1} y\right\} \\
& -\frac{h}{2 \lambda}\left\{\frac{\left[\phi-\left(1-p_{1}\right) x\right] B}{\left(1-p_{1}\right) x-\lambda}+(\phi-\lambda)\right. \\
& {\left[\frac{y}{\phi}-\frac{B}{\left(1-p_{1}\right) x-\lambda}\right]-\lambda\left(\frac{y}{x}-\frac{y}{\phi}\right)} \\
& \left.-p_{1} y-\frac{p_{2} y\left(\phi_{1}-\lambda\right)}{\phi_{1}}\right\}^{2}=-\frac{h}{2 \lambda} \alpha q_{2}\left(1-p_{1}\right) y^{2}
\end{aligned}
$$

$$
\begin{gathered}
-\frac{h_{1}}{2}\left\{2 \left\{\frac{\left[\phi-\left(1-p_{1}\right) x\right] B}{\left(1-p_{1}\right) x-\lambda}+(\phi-\lambda)\right.\right. \\
\left.\left[\frac{y}{\phi}-\frac{B}{\left(1-p_{1}\right) x-\lambda}\right]-\lambda\left(\frac{y}{x}-\frac{y}{\phi}\right)-p_{1} y\right\} \\
\left.-\frac{p_{2} y\left(\phi_{1}-\lambda\right)}{\phi_{1}}\right\}\left(\frac{p_{2} y}{\phi_{1}}\right) \\
+C_{B} \frac{1}{2}\left(\frac{1}{\lambda}+\frac{1}{\left(1-p_{1}\right) x-\lambda}\right) B^{2} . \\
=y G_{1}-B G_{2}-y^{2} G_{3}-B^{2} G_{4}-y B G_{5}-\frac{C_{0} y}{\phi^{\epsilon}}
\end{gathered}
$$

where $p_{1}, p_{2}, p_{3}, G_{1}, G_{2}, \ldots, G_{5}$ are expanded in Appendix A.

The manufacturer's total profit per unit time for Case I can be expressed as follows:

$$
\begin{aligned}
Z_{1}(y, B)= & \frac{\lambda}{\left(1-p_{1}\right)}\left[G_{1}-\frac{B G_{2}}{y}-y G_{3}-\frac{B^{2} G_{4}}{y}\right. \\
& \left.-B G_{5}-\frac{C_{0} y^{\in-1}}{\phi^{\epsilon}}\right]-\frac{\alpha q_{2} y}{2} .
\end{aligned}
$$

Thus, the expected total profit per unit time can be written as:

$$
\begin{gathered}
E\left[Z_{1}(y, B)\right]=\frac{\lambda}{\left(1-E\left[p_{1}\right]\right)}\left[E\left[G_{1}\right]-\frac{B E\left[G_{2}\right]}{y}\right. \\
\left.-y E\left[G_{3}\right]-\frac{B^{2} E\left[G_{4}\right]}{y}-B E\left[G_{5}\right]-\frac{C_{0} y^{\in-1}}{\phi^{\epsilon}}\right] \\
-\frac{E[\alpha] E\left[q_{2}\right] y}{2}
\end{gathered}
$$

where $E\left[p_{1}\right], E\left[p_{2}\right], E\left[p_{3}\right], E\left[G_{1}\right], E\left[G_{2}\right], \ldots, E\left[G_{5}\right]$ are expanded in Appendix B.

The function, as represented in Eq. (47), illustrates that when $\in \geq l$, the profit function is monotonically decreasing in $y$, indicating that the total cost function will be minimum when $y=0$, which is reasonably impractical. In practice, $y$ should be minimum, i.e. as much as required, which closely follows the JIT (Just-In-Time) manufacturing philosophy. Therefore, it is recommended that $\in<l$. Moreover, $C_{0}\left(T_{P}\right)$ is a concave function, which increases for $0<\in \leq l$. However, it decreases for $\in<0$.

The values indicating $\in<0$ signify a state in which the effect of learning nullifies the effect of forgetting and deterioration, resulting in a reduction in the setup costs with time.

\section{Case II: $T_{P} \geq T_{M}$ (without the effects of learning)}

When $T_{P} \geq T_{M}$, the following expression for the manufacturer's total cost is obtained as follows: 


$$
\begin{aligned}
T . C .2 & =C_{\max }+C_{p} y+d_{1}\left(\frac{\lambda y}{\phi(1-\alpha)}\right) \\
& +d_{2}\left\{\frac{\left[\phi-\left(1-p_{1}\right) x\right] B}{\left(1-p_{1}\right) x-\lambda}+(\phi-\lambda)\right. \\
& {\left.\left[\frac{y}{\phi}-\frac{B}{\left(1-p_{1}\right) x-\lambda}\right]-\frac{\lambda y}{\phi(1-\alpha)}-B\right\} } \\
& +d_{3}\left[\alpha y+(1-\alpha) q_{1} y\right]+C_{w} \alpha r y \\
& +C_{r}(1-\alpha) q_{1} y+C_{a} \alpha q_{2} y+u \alpha(1-r) y \\
& +h\left[\frac{1}{2} z_{1} t_{2}+\frac{1}{2} t_{3}\left(z_{1}+z_{5}\right)+\frac{1}{2} t_{4}\left(z_{5}+z_{3}\right)\right. \\
& \left.+\frac{1}{2} t_{6} z_{2}+\frac{1}{2} \alpha q_{2} y T\right]+h_{1} \frac{1}{2}\left(z_{3}+z_{2}\right) t_{5} \\
& +C_{B} \frac{1}{2}\left(t_{1}+t_{2}\right) B .
\end{aligned}
$$

The manufacturer's total profit for Case II is shown in the following:

$$
\begin{aligned}
& \text { T.P.2 }=s(1-\alpha) y+s \alpha r y+v \alpha(1-r) y-C_{\max } \\
& -C_{p} y-d_{1}\left(\frac{\lambda y}{\phi(1-\alpha)}\right) \\
& -d_{2}\left\{\frac{\left[\phi-\left(1-p_{1}\right) x\right] B}{\left(1-p_{1}\right) x-\lambda}+(\phi-\lambda)\right. \\
& \left.\left[\frac{y}{\phi}-\frac{B}{\left(1-p_{1}\right) x-\lambda}\right]-\frac{\lambda y}{\phi(1-\alpha)}-B\right\} \\
& -d_{3}\left[\alpha y+(1-\alpha) q_{1} y\right]-C_{w} \alpha r y \\
& -C_{r}(1-\alpha) q_{1} y-C_{a} \alpha q_{2} y-u \alpha(1-r) y \\
& -\frac{h}{2} \frac{\left[\phi-\left(1-p_{1}\right) x\right] B^{2}}{\left[\left(1-p_{1}\right) x-\lambda\right]^{2}} \\
& -h\left[\frac{y}{\phi}-\frac{B}{\left(1-p_{1}\right) x-\lambda}\right]\left[\frac{\left[\phi-\left(1-p_{1}\right) x\right] B}{\left(1-p_{1}\right) x-\lambda}\right] \\
& -\frac{h}{2}(\phi-\lambda)\left[\frac{y}{\phi}-\frac{B}{\left(1-p_{1}\right) x-\lambda}\right]^{2} \\
& -\frac{h}{2}\left(\frac{y}{x}-\frac{y}{\phi}\right)\left\{\frac{2\left[\phi-\left(1-p_{1}\right) x\right] B}{\left(1-p_{1}\right) x-\lambda}\right. \\
& +2(\phi-\lambda)\left[\frac{y}{\phi}-\frac{B}{\left(1-p_{1}\right) x-\lambda}\right] \\
& \left.-\lambda\left(\frac{y}{x}-\frac{y}{\phi}\right)-p_{1} y\right\}-\frac{h}{2 \lambda}\left\{\frac{\left[\phi-\left(1-p_{1}\right) x\right] B}{\left(1-p_{1}\right) x-\lambda}\right.
\end{aligned}
$$

$$
\begin{aligned}
& +(\phi-\lambda)\left[\frac{y}{\phi}-\frac{B}{\left(1-p_{1}\right) x-\lambda}\right]-\lambda\left(\frac{y}{x}-\frac{y}{\phi}\right) \\
& \left.-p_{1} y-\frac{p_{2} y\left(\phi_{1}-\lambda\right)}{\phi_{1}}\right\}^{2}-\frac{h}{2 \lambda} \alpha q_{2}\left(1-p_{1}\right) y^{2} \\
& -\frac{h_{1}}{2}\left\{\left\{\frac{\left[\phi-\left(1-p_{1}\right) x\right] B}{\left(1-p_{1}\right) x-\lambda}\right.\right. \\
& +(\phi-\lambda)\left[\frac{y}{\phi}-\frac{B}{\left(1-p_{1}\right) x-\lambda}\right] \\
& \left.\left.-\lambda\left(\frac{y}{x}-\frac{y}{\phi}\right)-p_{1} y\right\}^{2}-\frac{p_{2} y\left(\phi_{1}-\lambda\right)}{\phi_{1}}\right\} \\
& \left(\frac{p_{2} y}{\phi_{1}}\right)+C_{B} \frac{1}{2}\left(\frac{1}{\lambda}+\frac{1}{\left(1-p_{1}\right) x-\lambda}\right) B^{2} .
\end{aligned}
$$

Thus, the manufacturer's total profit can be written as:

$$
=y G_{1}-B G_{2}-y^{2} G_{3}-B^{2} G_{4}-y B G_{5}-C_{\max },
$$

where $p_{1}, p_{2}, p_{3}, G_{1}, G_{2}, \ldots, G_{5}$ are expanded in Appendix A.

The manufacturer's total profit per unit time can be written as:

$$
\begin{aligned}
Z_{2}(y, B)= & \frac{\lambda}{\left(1-p_{1}\right)}\left[G_{1}-\frac{B G_{2}}{y}-y G_{3}-\frac{B^{2} G_{4}}{y}\right. \\
& \left.-B G_{5}-C_{\max }\right]-\frac{\alpha q_{2} y}{2}
\end{aligned}
$$

Therefore, the expected total profit per unit time can be written as:

$$
\begin{aligned}
E\left[Z_{2}(y, B)\right]= & \frac{\lambda}{\left(1-E\left[p_{1}\right]\right)}\left[E\left[G_{1}\right]-\frac{B E\left[G_{2}\right]}{y}\right. \\
& -y E\left[G_{3}\right]-\frac{B^{2} E\left[G_{4}\right]}{y}-B E\left[G_{5}\right] \\
& \left.-C_{\max }\right]-\frac{y E[\alpha] E\left[q_{2}\right]}{2}
\end{aligned}
$$

where $E\left[p_{1}\right], E\left[p_{2}\right], E\left[p_{3}\right], E\left[G_{1}\right], E\left[G_{2}\right], \ldots, E\left[G_{5}\right]$ are expanded in Appendix B.

\section{Optimal policy}

The manufacturer aims to maximize the expected total profit per unit time by jointly optimizing the production amount and backorder quantity. In the following section, the concavity of the objective function is proved in the form of two lemmas.

Case I: $T_{P}<T_{M}$.

Lemma 1. The function of manufacturer's expected total profit per unit time for Case I is concave. 
Proof. In order to prove the global concavity of the expected profit function for this case, two second-order sufficient conditions of optimality should be satisfied:

$$
\begin{gathered}
\left(\frac{\partial^{2} E\left[Z_{1}(y, B)\right]}{\partial y^{2}}\right) \leq 0 ; \quad\left(\frac{\partial^{2} E\left[Z_{1}(y, B)\right]}{\partial B^{2}}\right) \leq 0, \\
\left(\frac{\partial^{2} E\left[Z_{1}(y, B)\right]}{\partial y \partial B}\right)^{2}-\left(\frac{\partial^{2} E\left[Z_{1}(y, B)\right]}{\partial y^{2}}\right) \\
\left(\frac{\partial^{2} E\left[Z_{1}(y, B)\right]}{\partial B^{2}}\right) \leq 0
\end{gathered}
$$

By taking the first-order partial derivative of $E\left[Z_{1}\right.$ $(y, B)]$ with respect to $y$, we obtain:

$$
\begin{gathered}
\frac{\partial}{\partial y} E\left[Z_{1}(y, B)\right]=\frac{\lambda}{1-E\left[p_{1}\right]}\left\{E\left[G_{2}\right] \frac{B}{y^{2}}-E\left[G_{3}\right]\right. \\
\left.+E\left[G_{4}\right] \frac{B^{2}}{y^{2}}-\frac{c_{0}(\epsilon-1) y^{(\epsilon-2)}}{\varphi^{\epsilon}}\right\} . \\
-\frac{E[\alpha] E\left[q_{2}\right]}{2} .
\end{gathered}
$$

Then, by taking second-order partial derivative of $E\left[Z_{1}(y, B)\right]$ with respect to $y$, we obtain:

$$
\begin{gathered}
\frac{\partial^{2}}{\partial y^{2}} E\left[Z_{1}(y, B)\right]=\frac{\lambda}{1-E\left[p_{1}\right]}\left\{-2 E\left[G_{2}\right] \frac{B}{y^{3}}\right. \\
\left.-2 E\left[G_{4}\right] \frac{B^{2}}{y^{3}}-\frac{c_{0}(\epsilon-1)(\epsilon-2) y^{(\epsilon-3)}}{\varphi^{\epsilon}}\right\}
\end{gathered}
$$

Again, by taking the first-order partial derivative of $E\left[Z_{1}(y, B)\right]$ with respect to $B$, we obtain:

$$
\begin{gathered}
\frac{\partial}{\partial B} E\left[Z_{1}(y, B)\right]=\frac{\lambda}{1-E\left[p_{1}\right]}\left\{-\frac{E\left[G_{2}\right]}{y}\right. \\
\left.-\frac{2 E\left[G_{4}\right] B}{y}-E\left[G_{5}\right]\right\},
\end{gathered}
$$

and by taking the second-order partial derivative of $E\left[Z_{1}(y, B)\right]$ with respect to $B$, we obtain:

$$
\frac{\partial^{2}}{\partial B^{2}} E\left[Z_{1}(y, B)\right]=-\frac{\lambda}{1-E\left[p_{1}\right]} \frac{2 E\left[G_{4}\right]}{y},
$$

and

$$
\begin{array}{r}
\frac{\partial^{2}}{\partial y \partial B} E\left[Z_{1}(y, B)\right]=\frac{\lambda}{1-E\left[p_{1}\right]} \\
\left\{\frac{E\left[G_{2}\right]}{y^{2}}+\frac{2 E\left[G_{4}\right] B}{y^{2}}\right\} .
\end{array}
$$

Thus, through Eqs. (54), (56), and (57), we obtain:

$$
\begin{gathered}
\left(\frac{\partial^{2}}{\partial y \partial B} E\left[Z_{1}(y, B)\right]\right)^{2}-\left(\frac{\partial^{2}}{\partial y^{2}} E\left[Z_{1}(y, B)\right]\right) \\
\left(\frac{\partial^{2}}{\partial B^{2}} E\left[Z_{1}(y, B)\right]\right)=\left(\frac{\lambda}{1-E\left[p_{1}\right]}\right)^{2} \\
*\left\{\frac{E^{2}\left[G_{2}\right]}{y^{4}}-\frac{2 c_{0}(\epsilon-1)(\epsilon-2) E\left[G_{4}\right] y^{\epsilon}}{y^{4} \varphi^{\epsilon}}\right\} .
\end{gathered}
$$

The three conditions of concavity are derived in Appendix C.

Lemma 2. The optimal solution $\left(y^{*}, B^{*}\right)$ that maximizes the manufacturer's expected total profit per unit time for Case I is written as:

$$
\begin{aligned}
& y^{*}= \\
& {\left[\frac{4(1-\epsilon) c_{0} E\left[G_{4}\right]}{p^{\in}\left\{4 E\left[G_{4}\right]\left\{E\left[G_{3}\right]+\frac{E[\alpha] E\left[q_{2}\right]}{2}\right\}-E^{2}\left[G_{3}\right]\right\}}\right]^{1 / 2-\epsilon},}
\end{aligned}
$$

and:

$$
B^{*}=-\frac{E\left[G_{2}\right]+E\left[G_{5}\right] y}{2 E\left[G_{4}\right]} .
$$

Proof. In order to find the optimal values of $y$ and $B$, say $y^{*}$ and $B^{*}$, that maximize $E\left[Z_{1}(y, B)\right]$, the first-order necessary condition of optimality must be equated to zero, i.e.:

$$
\frac{\partial}{\partial y} E\left[Z_{1}(y, B)\right]=0 \quad \text { and } \quad \frac{\partial}{\partial B} E\left[Z_{1}(y, B)\right]=0
$$

By setting Eq. (53) equal to zero, we get:

$$
\begin{array}{r}
\frac{\lambda}{1-E\left[p_{1}\right]}\left\{-2 E\left[G_{2}\right] \frac{B}{y^{3}}-2 E\left[G_{4}\right] \frac{B^{2}}{y^{3}}\right. \\
\left.-\frac{c_{0}(\epsilon-1)(\epsilon-2) y^{(\epsilon-3)}}{\varphi^{\epsilon}}\right\}=0 .
\end{array}
$$

By setting Eq. (55) equal to zero, we get:

$$
\begin{aligned}
& \frac{\lambda}{1-E\left[p_{1}\right]}\left\{-\frac{E\left[G_{2}\right]}{y}-\frac{2 E\left[G_{4}\right] B}{y}-E\left[G_{5}\right]\right\}=0 . \\
& \Rightarrow B^{*}=-\frac{E\left[G_{2}\right]+E\left[G_{5}\right] y}{2 E\left[G_{4}\right]} .
\end{aligned}
$$

Substitute the value of $B$ into Eq. (59) to calculate the value for $y$, i.e.:

$$
\begin{aligned}
& y^{*}= \\
& {\left[\frac{4(1-\epsilon) c_{0} E\left[G_{4}\right]}{p^{\in}\left\{4 E\left[G_{4}\right]\left\{E\left[G_{3}\right]+\frac{E[\alpha] E\left[q_{2}\right]}{2}\right\}-E^{2}\left[G_{3}\right]\right\}}\right]^{1 / 2-\epsilon} .}
\end{aligned}
$$

Hence, $y^{*}$ and $B^{*}$ are the optimal values of $y$ and $B$ for Case I. 
Case II: $T_{M} \geq T_{P}$.

Lemma 3. The function of manufacturer's expected total profit per unit time for Case II is concave.

Proof. In order to prove the global concavity of the expected profit function, the following two secondorder sufficient conditions of optimality for this case should also be satisfied:

$$
\begin{gathered}
\left(\frac{\partial^{2} E\left[Z_{2}(y, B)\right]}{\partial y^{2}}\right) \leq 0 ;\left(\frac{\partial^{2} E\left[Z_{2}(y, B)\right]}{\partial B^{2}}\right) \leq 0 \\
\text { and }\left(\frac{\partial^{2} E\left[Z_{2}(y, B)\right]}{\partial y \partial B}\right)^{2}-\left(\frac{\partial^{2} E\left[Z_{2}(y, B)\right]}{\partial y^{2}}\right) \\
\left(\frac{\partial^{2} E\left[Z_{2}(y, B)\right]}{\partial B^{2}}\right) \leq 0 .
\end{gathered}
$$

By taking the first-order partial derivative of $E\left[Z_{2}(y, B)\right]$ with respect to $y$, we obtain:

$$
\begin{gathered}
\frac{\partial}{\partial y} E\left[Z_{2}(y, B)\right]=\frac{\lambda}{1-E\left[p_{1}\right]}\left\{E\left[G_{2}\right] \frac{B}{y^{2}}-E\left[G_{3}\right]\right. \\
\left.+E\left[G_{4}\right] \frac{B^{2}}{y^{2}}+\frac{C_{\max }}{y^{2}}\right\}-\frac{E[\alpha] E\left[q_{2}\right]}{2} .
\end{gathered}
$$

Then, by taking the second-order partial derivative of $E\left[Z_{2}(y, B)\right]$ with respect to $y$, we obtain:

$$
\begin{gathered}
\frac{\partial^{2}}{\partial y^{2}} E\left[Z_{2}(y, B)\right]=\frac{\lambda}{1-E\left[p_{1}\right]}\left\{-2 E\left[G_{2}\right] \frac{B}{y^{3}}\right. \\
\left.-2 E\left[G_{4}\right] \frac{B^{2}}{y^{3}}-\frac{2 C_{\max }}{y^{3}}\right\} \leq 0,
\end{gathered}
$$

by taking the first-order partial derivative of $E\left[Z_{2}(y, B)\right]$ with respect to $B$, we obtain:

$$
\begin{aligned}
\frac{\partial}{\partial B} E\left[Z_{2}(y, B)\right] & =\frac{\lambda}{1-E\left[p_{1}\right]} \\
& \left\{-\frac{E\left[G_{2}\right]}{y}-\frac{2 E\left[G_{4}\right] B}{y}-E\left[G_{5}\right]\right\},
\end{aligned}
$$

and by taking the second-order partial derivative of $E\left[Z_{2}(y, B)\right]$ with respect to $B$, we obtain:

$$
\frac{\partial^{2}}{\partial B^{2}} E\left[Z_{2}(y, B)\right]=-\frac{\lambda}{1-E\left[p_{1}\right]} \frac{2 E\left[G_{4}\right]}{y} \leq 0 .
$$

Also:

$$
\frac{\partial^{2}}{\partial y \partial B} E\left[Z_{2}(y, B)\right]=\frac{E\left[G_{2}\right]}{y^{2}}+\frac{2 E\left[G_{4}\right] B}{y^{2}} .
$$

Thus, through Eqs. (64), (66), and (67), we obtain:

$$
\begin{gathered}
\left(\frac{\partial^{2}}{\partial y \partial B} E\left[Z_{2}(y, B)\right]\right)^{2}-\left(\frac{\partial^{2}}{\partial y^{2}} E\left[Z_{2}(y, B)\right]\right) \\
\left(\frac{\partial^{2}}{\partial B^{2}} E\left[Z_{2}(y, B)\right]\right)=\frac{E^{2}\left[G_{2}\right]}{y^{4}} \\
-\frac{4 E\left[G_{4}\right] C_{\max }}{y^{4}} .
\end{gathered}
$$

The conditions of concavity are derived in Appendix D.

Lemma 4. The optimal solution $\left(y^{*}, B^{*}\right)$ that maximizes the manufacturer's expected total profit per unit time is written as:

$$
\begin{aligned}
y^{*} & =\sqrt{\frac{2 \lambda\left(B E\left[G_{2}\right]+B^{2} E\left[G_{4}\right]+C_{\max }\right)}{2 \lambda E\left[G_{3}\right]+E[\alpha] E\left[q_{2}\right]\left(1-E\left[p_{1}\right]\right)}}, \\
B^{*} & =-\frac{E\left[G_{2}\right]+E\left[G_{5}\right] y}{2 E\left[G_{4}\right]} .
\end{aligned}
$$

Proof. In order to find the optimal values of $y$ and $B$, or $y^{*}$ and $B^{*}$, that maximize $E\left[Z_{2}(y, B)\right]$, the firstorder necessary condition of optimality must be equal to zero, i.e.:

$$
\begin{aligned}
& \frac{\partial}{\partial y} E\left[Z_{2}(y, B)\right]=0, \quad \text { and }: \\
& \frac{\partial}{\partial B} E\left[Z_{2}(y, B)\right]=0 .
\end{aligned}
$$

By setting Eq. (63) equal to zero, we get:

$$
\begin{aligned}
& \frac{\lambda}{1-E\left[p_{1}\right]}\left\{E\left[G_{2}\right] \frac{B}{y^{2}}-E\left[G_{3}\right]+E\left[G_{4}\right] \frac{B^{2}}{y^{2}}+\frac{C_{\max }}{y^{2}}\right\} \\
& -\frac{E[\alpha] E\left[q_{2}\right]}{2}=0 \\
& \Rightarrow y^{*}=\sqrt{\frac{2 \lambda\left(B E\left[G_{2}\right]+B^{2} E\left[G_{4}\right]+C_{\max }\right)}{2 \lambda E\left[G_{3}\right]+E[\alpha] E\left[q_{2}\right]\left(1-E\left[p_{1}\right]\right)}}
\end{aligned}
$$

By setting Eq. (65) equal to zero, we get:

$$
\begin{aligned}
& \frac{\lambda}{1-E\left[p_{1}\right]}\left\{-\frac{E\left[G_{2}\right]}{y}-\frac{2 E\left[G_{4}\right] B}{y}-E\left[G_{5}\right]\right\}=0 \\
& \Rightarrow B^{*}=-\frac{E\left[G_{2}\right]+E\left[G_{5}\right] y}{2 E\left[G_{4}\right]} .
\end{aligned}
$$

This value of $B$ given in Eq. (72) is substituted into Eq. (70), to attain the final value of $y$ which is given by Eq. (73), shown in Box I.

Hence, $y^{*}$ and $B^{*}$ are the optimal values of $y$ and B for Case II. 


$$
\Rightarrow y^{*}=\sqrt{\frac{2 \lambda\left\{\left[-\frac{E\left[G_{2}\right]+E\left[G_{5}\right] y}{2 E\left[G_{4}\right]}\right] E\left[G_{2}\right]+\frac{\left[E\left[G_{2}\right]+E\left[G_{5}\right] y\right]^{2}}{4 E\left[G_{4}\right]}+C_{\max }\right\}}{2 \lambda E\left[G_{3}\right]+E[\alpha] E\left[q_{2}\right]\left(1-E\left[p_{1}\right]\right)}} .
$$

Box I

\section{Numerical analysis}

In order to validate the developed formulation, this section presents the numerical analysis, gives two examples, and solves them for two cases, namely with and without the effects of learning in setup cost. Furthermore, this section draws a comparison in terms of any change in optimal profit values between one-way and two-way inspection plans at the manufacturer's end.

\subsection{Examples}

This subsection authenticates the hypothesis using two examples, each solved for the abovementioned cases of the learning effects. Tables 2 and 3 demonstrate the parameter values for two numerical examples that are similar to or different from those used in the study conducted by Wee et al. [38]. Table 4 depicts the optimal values of the mentioned two examples.

Table 2. Numerical data from the model proposed by Wee et al. [38] for Numerical 1 and Numerical 2.

\begin{tabular}{lclll}
\hline \multicolumn{1}{c}{ Description } & Symbol & Numerical 1 & Numerical 2 & Unit \\
\hline Production rate & $\varphi$ & $2,00,000$ & $1,50,000$ & Units/cycle \\
Screening cost during production & $d_{1}$ & 0.5 & 0.6 & \$/unit \\
Shortage cost & $c_{B}$ & 10 & 14 & \$/unit/year \\
Screening rate & $x$ & $1,75,200$ & $1,00,000$ & Units/year \\
Setup cost & $C_{0}$ & 100 & 120 & \$/cycle \\
Purchase cost & $c$ & 25 & 30 & \$/unit \\
Salvage cost & $v$ & 16 & 20 & $\$ /$ unit \\
Holding cost & $h$ & 5 & 6 & $\$ /$ unit/year \\
\hline
\end{tabular}

Table 3. Other parameters for Numerical 1 and Numerical 2.

\begin{tabular}{|c|c|c|c|c|}
\hline Description & Symbol & Numerical 1 & Numerical 2 & Unit \\
\hline Defect proportion & $A$ & $\mathrm{U} \sim(0.4,0.6)$ & $\mathrm{U} \sim(0.5,0.15)$ & \\
\hline Type-I error proportion & $q_{1}$ & $\mathrm{U} \sim(0.05,0.15)$ & $\mathrm{U} \sim(0.2,0.8)$ & \\
\hline Type-II error proportion & $q_{2}$ & $\mathrm{U} \sim(0.1,0.3)$ & $\mathrm{U} \sim(0.2,0.8)$ & \\
\hline Rework proportion & $R$ & $\mathrm{U} \sim(0.5,0.7)$ & $\mathrm{U} \sim(0.5,0.8)$ & \\
\hline Probability density function & $f(\alpha)$ & $1 /(0.6-0.4)$ & $1 /(0.15-0.5)$ & \\
\hline Probability density function & $f\left(q_{1}\right)$ & $1 /(0.3-0.1)$ & $1 /(0.8-0.2)$ & \\
\hline Probability density function & $f\left(q_{2}\right)$ & $1 /(0.3-0.1)$ & $1 /(0.8-0.2)$ & \\
\hline Probability density function & $f(r)$ & $1 /(0.7-0.5)$ & $1 /(0.8-0.5)$ & \\
\hline Demand rate & $\lambda$ & 90,000 & 50,000 & Units/year \\
\hline Shape factor & $\epsilon$ & 0.2 & 0.3 & \\
\hline Rework rate & $\varphi_{1}$ & 80,000 & 40,000 & Units/cycle \\
\hline Selling price & $S$ & 60 & 70 & $\$ /$ unit \\
\hline Post-production screening cost & $d_{2}$ & 0.6 & 0.7 & $\$ /$ unit \\
\hline Second screening cost & $d_{3}$ & 0.7 & 0.8 & $\$ /$ unit \\
\hline Type-I error cost & $c_{r}$ & 10 & 12 & $\$ /$ unit \\
\hline Type-II error cost & $c_{a}$ & 12 & 12 & $\$ /$ unit \\
\hline Rework cost & $c_{W}$ & 8 & 9 & $\$ /$ unit \\
\hline Disposal cost & $u$ & 2 & 3 & $\$ /$ unit \\
\hline Maximum setup cost & $C_{\max }$ & - & - & $\$ /$ cycle \\
\hline Holding cost during rework & $h_{1}$ & 6 & 6 & $\$ /$ unit \\
\hline
\end{tabular}


Table 4. Optimal inventory policy under the effect of learning.

\begin{tabular}{lllll}
\hline \multicolumn{1}{c}{ Description } & Symbol & Numerical 1 & Numerical 2 & \multicolumn{1}{c}{ Unit } \\
\hline Production quantity & $y^{*}$ & 1,648 & 701 & Units/cycle \\
Backorder quantity & $B^{*}$ & 267 & 109 & Units/cycle \\
Expected total profit per unit time & $E\left[Z^{*}(y, B)\right]$ & $30,55,994$ & $18,60,999$ & $\$ /$ year \\
Cycle length & $T^{*}$ & 6.55 & 4.94 & Days \\
\hline
\end{tabular}

Table 5. Comparison between one-way and two-way inspection plans.

\begin{tabular}{ccccc}
\hline Description & Symbol & Numerical 1 & Numerical 2 & Unit \\
\hline One-way inspection & $E\left[Z^{*}(y, B)\right]$ & $30,39,578$ & $18,10,119$ & $\$ /$ year \\
Two-way inspection & $E\left[Z^{*}(y, B)\right]$ & $30,55,994$ & $18,60,999$ & $\$ /$ year \\
\hline
\end{tabular}

Table 6. Impact of $\epsilon$ on optimal replenishment policy.

\begin{tabular}{ccccccc}
\hline $\boldsymbol{\epsilon}$ & $\boldsymbol{T}^{*}$ & $\boldsymbol{y}^{*}$ & $\boldsymbol{B}^{*}$ & $\boldsymbol{T}^{*}$ & $\boldsymbol{E}\left[\boldsymbol{Z}^{*}(\boldsymbol{y}, \boldsymbol{B})\right]$ & $\boldsymbol{\%}$ loss \\
\hline 0.1 & 4.12 & $2,258.45$ & 366.89 & 8.98 & $30,54,899.54$ & -25.05 \\
0.2 & 3.01 & $1,648.97$ & 267.88 & 6.55 & $30,55,994.14$ & -25.09 \\
0.3 & 2.10 & $1,149.54$ & 186.74 & 4.57 & $30,56,944.69$ & -25.13 \\
0.4 & 1.38 & 756.22 & 122.85 & 3.01 & $30,57,746.91$ & -25.17 \\
0.5 & 0.84 & 461.71 & 75.01 & 1.84 & $30,58,400.44$ & -25.19 \\
0.6 & 0.47 & 255.16 & 41.45 & 1.01 & $30,58,909.70$ & -25.21 \\
0.7 & 0.46 & 251.86 & 41.64 & 1.01 & $30,60,737.84$ & -25.29 \\
0.8 & 0.09 & 47.16 & 7.66 & 0.19 & $30,59,541.11$ & -25.24 \\
\hline
\end{tabular}

Table 7. Impact of $\alpha$ on optimal replenishment policy.

\begin{tabular}{ccccccc}
\hline $\boldsymbol{\alpha}$ & $\boldsymbol{y}^{*}$ & $\boldsymbol{B}^{*}$ & $\boldsymbol{T}^{*}$ & $\boldsymbol{E . T . C . U . *}$ & $\boldsymbol{E . T . R . U . *}$ & $\boldsymbol{E}\left[\boldsymbol{Z}^{*}(\boldsymbol{y}, \boldsymbol{B})\right]$ \\
\hline 0.01 & $1,681.62$ & 272.75 & 6.79 & $23,07,399.23$ & $54,04,698.80$ & $30,97,299.57$ \\
0.03 & $1,664.67$ & 270.26 & 6.67 & $23,37,406.30$ & $54,14,210.53$ & $30,76,804.23$ \\
0.05 & $1,648.98$ & 267.88 & 6.55 & $23,67,883.41$ & $54,23,877.55$ & $30,55,994.14$ \\
0.07 & $1,634.43$ & 265.60 & 6.44 & $23,98,841.05$ & $54,33,703.70$ & $30,34,862.66$ \\
0.09 & $1,620.97$ & 263.41 & 6.34 & $24,30,289.94$ & $54,43,692.95$ & $30,13,403.01$ \\
\hline
\end{tabular}

\subsection{Comparison of profit values between one-way and two-way inspection plans}

This subsection draws a contrast regarding the expected total profit per unit time for the abovementioned two cases when both are solved with and without the two-way inspection plans.

Table 5 shows that it is of great financial interest for the manufacturer to practice the second inspection before taking the final decision of salvaging the defectives or sending the lot for rework. Another intuitive reason to opt for the second inspection plan is that it is easier to deliver a quality error-free inspection to a smaller batch of only accumulated defectives rather than to the whole production lot. In this respect, a small investment in this direction pays back with higher returns. By extracting the complete fraction of wrongly classified perfect items as defective, the manufacturer is able to reduce their financial losses caused by committing Type-I error as its effect gets nullified by the re-inspection. Therefore, even by assuming inspection errors in the model, their impacts are proficiently controlled.

\section{Sensitivity analysis}

The present section presents the robustness of the developed model by observing the changes in the objective values while the model parameters alter.

The outcome of changes in the defect parameters $\alpha, q_{1}, q_{2}$, and $r$ and the shape parameter $\epsilon$ is observed in the optimal production quantity $\left(y^{*}\right)$, optimal backorder quantity $\left(B^{*}\right)$, optimal cycle length $\left(T^{*}\right)$, optimal total cost per unit time (T.C.U.*), and optimal expected total profit per unit time $E\left[Z^{*}(y, B)\right]$, as shown in the following.

Tables 6 to 10 provide the managerial insights. 
Table 8. Impact of $q_{1}$ on optimal replenishment policy.

\begin{tabular}{ccccccc}
\hline $\boldsymbol{q}_{\mathbf{1}}$ & $\boldsymbol{y}^{*}$ & $\boldsymbol{B}^{*}$ & $\boldsymbol{T}^{*}$ & $\boldsymbol{E . T . C . U .}{ }^{*}$ & $\boldsymbol{E . T . R . U . *}$ & $\boldsymbol{E}\left[\boldsymbol{Z}^{*}(\boldsymbol{y}, \boldsymbol{B})\right]$ \\
\hline 0 & $1,648.97$ & 267.88 & 6.55 & $23,58,548.20$ & $54,23,877.55$ & $30,65,329.35$ \\
0.01 & $1,648.98$ & 267.88 & 6.55 & $23,67,883.41$ & $54,23,877.55$ & $30,55,994.14$ \\
0.02 & $1,648.97$ & 267.88 & 6.55 & $23,77,218.61$ & $54,23,877.55$ & $30,46,658.94$ \\
0.03 & $1,648.97$ & 267.88 & 6.55 & $23,86,553.82$ & $54,23,877.55$ & $30,37,323.74$ \\
0.04 & $1,648.97$ & 267.88 & 6.55 & $23,95,889.02$ & $54,23,877.55$ & $30,27,988.53$ \\
\hline
\end{tabular}

Table 9. Impact of $q_{2}$ on optimal replenishment policy.

\begin{tabular}{ccccccc}
\hline $\boldsymbol{q}_{\mathbf{2}}$ & $\boldsymbol{y}^{*}$ & $\boldsymbol{B}^{*}$ & $\boldsymbol{T}^{*}$ & $\boldsymbol{E . T . C . U .}{ }^{*}$ & $\boldsymbol{E . T . R . U .}{ }^{*}$ & $\boldsymbol{E}\left[\boldsymbol{Z}^{*}(\boldsymbol{y}, \boldsymbol{B})\right]$ \\
\hline 0 & $1,651.19$ & 268.24 & 6.56 & $23,66,777.24$ & $54,29,387.76$ & $30,62,610.51$ \\
0.01 & $1,650.08$ & 268.06 & 6.56 & $23,67,330.33$ & $54,26,632.65$ & $30,59,302.33$ \\
0.03 & $1,647.87$ & 267.70 & 6.55 & $23,68,436.49$ & $54,21,122.45$ & $30,52,685.96$ \\
0.02 & $1,648.98$ & 267.88 & 6.55 & $23,67,883.41$ & $54,23,877.55$ & $30,55,994.14$ \\
0.04 & $1,646.77$ & 267.52 & 6.54 & $23,68,989.57$ & $54,18,367.35$ & $30,49,377.78$ \\
\hline
\end{tabular}

Table 10. Impact of $r$ on optimal replenishment policy.

\begin{tabular}{ccccccc}
\hline $\boldsymbol{r}$ & $\boldsymbol{y}^{*}$ & $\boldsymbol{B}^{*}$ & $\boldsymbol{T}^{*}$ & $\boldsymbol{E} . \boldsymbol{T} . \boldsymbol{C . U} .^{*}$ & $\boldsymbol{E . T . R . U .}{ }^{*}$ & $\boldsymbol{E}\left[\boldsymbol{Z}^{*}(\boldsymbol{y}, \boldsymbol{B})\right]$ \\
\hline 0 & $1,752.79$ & 254.91 & 6.75 & $24,25,417.21$ & $54,70,105.26$ & $30,44,688.05$ \\
0.5 & $1,665.80$ & 265.83 & 6.59 & $23,77,225.96$ & $54,31,384.62$ & $30,54,158.66$ \\
0.6 & $1,648.97$ & 267.88 & 6.55 & $23,67,883.41$ & $54,23,877.55$ & $30,55,994.14$ \\
0.7 & $1,632.35$ & 269.88 & 6.52 & $23,58,635.91$ & $54,16,446.70$ & $30,57,810.79$ \\
0.8 & $1,615.93$ & 271.85 & 6.49 & $23,49,482.00$ & $54,09,090.91$ & $30,59,608.90$ \\
\hline
\end{tabular}

Table 6 shows that with an increase in the value of shape factor $\epsilon$, the setup of production process is frequently done, which results in a decrease in the backorders $\left(B^{*}\right)$ since there is sufficient quantity to satisfy the demand of the retailer. The production run length $\left(T p^{*}\right)$, cycle time $\left(T^{*}\right)$, lot size $\left(y^{*}\right)$, and expected total cost $\left(T . C . U^{*}\right)$ per unit time are quite sensitive to the changes in the shape factor. This decrease in the loss percentage, compared to the traditional EOQ models, can be justified by the extensive crashing in the duration of the production run length and setup cost.

As shown in Table 7 , the value for optimal expected total profit per unit time $E\left[Z^{*}(y, B)\right]$ shows a declining trend and an optimal backorder level $\left(B^{*}\right)$, while the optimal values for production quantity $\left(y^{*}\right)$, cycle length $\left(T^{*}\right)$, total revenue per unit time $($ T.R.U.*), and total cost per unit time (T.C.U.*) increase as the defect proportion $(\alpha)$ increases. With an increased proportion of defects in the system, there will be a higher sale and hence, return of defectives. This not only brings about considerable monetary loss for the firm, but also damages its reputation. However, due to more sales of scrap items, an increase in the revenue is observed. On the other hand, the firm is not able to compensate for the losses incurred yet. Thus the overall profit of the system decreases. Since the demand is compensated for only by perfect items, the manufacturer needs to produce more than the demand, hence increasing the production quantity. Therefore, it is advisable for the operations manager to improvise their production system to substantially reduce the defect proportion.

According to Table 8, while the proportion of Type-I error increases $\left(q_{1}\right)$, the optimal production quantity $\left(y^{*}\right)$ and expected value of total profit per unit time $\left(Z^{*}(y, B)\right)$ show declining trends. However, total revenue per unit time $\left(T . R . U^{*}\right)$ and total cost per unit time (T.C.U.*) experience elevation in their values. Due to Type-I error, the manufacturer endures a direct financial loss since the screening process and inspection team are not competent enough to carry out the process without errors. Consequently, there is a significant fall in the profit values as the non-defectives are sold at a reduced price by mistake. In this scenario, the manufacturer is unable to achieve the maximum possible sales. Therefore, it is beneficial for them to reduce their production quantity to minimize losses resulting from misclassification. Revenue indirectly increases as a result of salvaging of non-defectives in 
a less restrictive inventory. However, any increase in the total cost dominates the increase in revenue, thus decreasing the overall profit values.

According to Table 9 , with increase in the proportion of Type-II error $\left(q_{2}\right)$, a considerable decline in the optimal values of expected total profit per unit time $\left(Z^{*}(y, B)\right)$ and total revenue per unit time (T.R.U.*) is observed, while the cost values show significant increase. No significant change is observed in the values of optimal backorder level $\left(B^{*}\right)$, optimal production quantity $\left(y^{*}\right)$, and cycle length $\left(T^{*}\right)$. Since TypeII error brings about sales returns, which are either entertained with full-price refunds or replaced by perfect products, it affects the revenue part considerably. Moreover, it also causes penalty and goodwill loss to the firm with which the managers are concerned. It also leads to an increase in the cost components. The constancy of demands and shortages is justified by the fact that the manager is able to maintain the demand despite some sales returns. In this particular scenario, it is beneficial for the operation manager to strengthen their screening team so as to reduce such damaging screening errors.

As observed in Table 10, with an increase in the proportion of reworked items $(r)$, the optimal production quantity $\left(y^{*}\right)$, cycle length $\left(T^{*}\right)$, total cost per unit time (T.C.U.*), and total revenue per unit time $\left(T . R . U^{*}\right)$ decrease, while the optimal values of the expected total profit per unit time $\left(Z^{*}(y, B)\right)$ and optimal backorder level $\left(B^{*}\right)$ increase. Logically, there is a cost associated with the rework process, yet it is compensated for with an increase in the sales of perfect items. Therefore, the overall profit of the system increases. As a result of rework process, the production quantity lessens since the number of perfect items considerably increases, thereby decreasing the need for producing more items to meet the demands. Consequently, the cycle length also decreases.

\section{Conclusion}

In the current manufacturing scenario, the main challenge is to establish an efficient inventory model that considers the major and minor concerns of the system. The problems associated with the production system are mainly associated with the production of defectives, screening, and management. To this end, the present paper developed an inventory model for finite production system, which was presumed to be imperfect and produce defectives at a uniform rate. To supply only good products to the customers, the screening process plays a key role for the manufacturer. In contrast to the previous studies, the present model was explored at two stages of inspection practices, with screening errors incorporated only in the first stage. To validate the hypothesis, the numerical section presented a comparison of the optimal profit values in the presence of one-way and two-way inspection techniques. Various managerial implications obtained are as follows:

- The results showed that the losses resulting from the manufacturer's performance through discarding the perfect items by mistake (an outcome of Type-I error) in the first inspection process were compensated for by means of a small investment in the second inspection error-free process;

- With a closer scrutiny of the second stage of inspection, the manufacturer was able to completely extract the misclassified perfect items before making the final decision for rework and thus, avoid some undue expenses related to rework cost or unnecessary salvaging;

- Even in prevailing imperfect quality and screening environment, the manufacturer was able to raise the revenue by selling a larger number of perfect items at the markup price using the scenario of no-second-time inspection. In this regard, the model successfully diminished the relatively harmful impact of Type-I error as compared to the effect of Type-II error;

- In addition, in an attempt made to cut down the escalating cost components, the process of learning helped the manufacturer reduce the setup cost of the production system in the present model. Economically, it made sense to employ the process of learning to enhance the organization's performance, authenticated by a decrease in loss percentage;

- In general, it is advisable for the manufacturer to reduce the percentage of defectives through a correct/careful production process since they significantly increased the defect-related costs.

The model puts forth some very interesting and useful scenarios including Type-I and Type-II inspection errors, revenue management through two-way inspection, reduction in setup costs through time-dependent learning, rework operations, etc. Therefore, the present model is preferable to other models that do not include such practical settings since it holds wide applicability in real-time manufacturing industries.

\section{Suggestions for further research and research limitations}

The model can be extended in a number of ways through adopting varying demand patterns. In addition, it would be interesting to develop an integrated vendor-buyer model in this direction. The model can also be extended to deteriorating products, taking into account the impact of preservation technology. Consideration of environmental factors in transportation 
and production would be another worthy contribution. Finally, the presented model is restricted by limited storage space for the manufacturer with various exact cash flows, which can be a major consideration for further research.

\section{References}

1. Porteus, E.L. "Optimal lot sizing, process quality improvement and setup cost reduction", Oper. Res., 34(1), pp. 137-144 (1986).

2. Rosenblatt, M.J. and Lee, H.L. "Economic production cycles with imperfect production processes", IIE T., 18(1), pp. 48-55 (1986).

3. Lee, H.L. and Rosenblatt, M.J. "Simultaneous determination of production cycle and inspection schedules in a production system", Manage. Sci., 33(9), pp. 1125-1136 (1987).

4. Kim, C.H. and Hong, Y. "An optimal production run length in deteriorating production processes", Int. J. Prod. Econ., 58(2), pp. 183-189 (1999).

5. Ben-Daya, M. and Hariga, M. "Economic lot scheduling problem with imperfect production processes", $J$. Oper. Res. Soc., 51(7), pp. 875-881 (2000).

6. Salameh, M.K. and Jaber, M.Y. "Economic production quantity model for items with imperfect quality", Int. J. Prod. Econ., 64(1), pp. 59-64 (2000).

7. Cárdenas-Barrón, L.E. "Observation on:"Economic production quantity model for items with imperfect quality" [Int. J. Production Economics 64 (2000) 5964]", Int. J. Prod. Econ., 67(2), p. 201 (2000).

8. Huang, C.K. "An integrated vendor-buyer cooperative inventory model for items with imperfect quality", Prod. Plan. Control, 13(4), pp. 355-361 (2002).

9. Chung, K.J. and Hou, K.L. "An optimal production run time with imperfect production processes and allowable shortages", Comput. Oper. Res., 30(4), pp. 483-490 (2003).

10. Yeh, R.H., Ho, W.T., and Tseng, S.T. "Optimal production run length for products sold with warranty", Eur. J. Oper. Res., 120(3), pp. 575-582 (2000).

11. Ben-Daya, M. and Rahim, A. "Optimal lot-sizing, quality improvement and inspection errors for multistage production systems", Int. J. Prod. Res., 41(1), pp. 65-79 (2003).

12. Huang, C.K. "An optimal policy for a single-vendor single-buyer integrated production-inventory problem with process unreliability consideration", Int. J. Prod. Econ., 91(1), pp. 91-98 (2004).

13. Hsieh, C.C. and Lee, Z.Z. "Joint determination of production run length and number of standbys in a deteriorating production process", Eur. J. Oper. Res., 162(2), pp. 359-371 (2005).

14. Chen, C.K. and Lo, C.C. "Optimal production run length for products sold with warranty in an imperfect production system with allowable shortages", Math. Comput. Model., 44(3), pp. 319-331 (2006).
15. Wee, H.M., Yu, J., and Chen, M.C. "Optimal inventory model for items with imperfect quality and shortage backordering", Omega, 35(1), pp. 7-11 (2007).

16. Raouf, A., Jain, J.K., and Sathe, P.T. "A costminimization model for multicharacteristic component inspection", AIIE T., 15(3), pp. 187-194 (1983).

17. Duffuaa, S.O. and Khan, M. "An optimal repeat inspection plan with several classifications", J. Oper. Res. Soc., 53(9), pp. 1016-1026 (2002).

18. Duffuaa, S.O. and Khan, M. "Impact of inspection errors on the performance measures of a general repeat inspection plan", Int. J. Prod. Res., 43(23), pp. 49454967 (2005).

19. Zhou, Y., Chen, C., Li, C., and Zhong, Y. "A synergic economic order quantity model with trade credit, shortages, imperfect quality and inspection errors", Appl. Math. Model., 40(2), pp. 1012-1028 (2016).

20. Al-Salamah, M. "Economic production quantity in batch manufacturing with imperfect quality, imperfect inspection, and destructive and non-destructive acceptance sampling in a two-tier market", Comput. Ind. Eng., 93, pp. 275-285 (2016).

21. Khan, M., Hussain, M., and Cárdenas-Barrón, L.E. "Learning and screening errors in an EPQ inventory model for supply chains with stochastic lead time demands", Int. J. Prod. Res., 55(16), pp. 4816-4832 (2017).

22. Khanna, A., Kishore, A., and Jaggi, C.K. "Strategic production modeling for defective items with imperfect inspection process, rework, and sales return under twolevel trade credit", Int. J. Ind. Eng. Comput., 8(1), pp. 85-118 (2017).

23. Pal, S. and Mahapatra, G.S. "A manufacturingoriented supply chain model for imperfect quality with inspection errors, stochastic demand under rework and shortages", Comput. Ind. Eng., 106, pp. 299-314 (2017).

24. Sett, B.K., Sarkar, S., and Sarkar, B. "Optimal buffer inventory and inspection errors in an imperfect production system with preventive maintenance", T. Int. J. Adv. Manuf. Tech., 90(1-4), pp. 545-560 (2017).

25. Hayek, P.A. and Salameh, M.K. "Production lot sizing with the reworking of imperfect quality items produced", Prod. Plan. Control, 12(6), pp. 584-590 (2001).

26. Chiu, Y.P. "Determining the optimal lot size for the finite production model with random defective rate, the rework process, and backlogging", Eng. Optim., 35(4), pp. 427-437 (2003).

27. Chiu, S.W., Gong, D.C., and Wee, H.M. "Effects of random defective rate and imperfect rework process on economic production quantity model", Jap. J. Ind. Appl. Math., 21(3), pp. 375-389 (2004).

28. Chiu, Y.S.P., Lin, H.D., and Cheng, F.T. "Optimal production lot sizing with backlogging, random defective rate, and rework derived without derivatives", P. I. Mech. Eng. B-J. Eng., 220(9), pp. 1559-1563 (2006). 
29. Chiu, S.W., Ting, C.K., and Chiu, Y.S.P. "Optimal production lot sizing with rework, scrap rate, and service level constraint", Math. Comput. Model., 46(3), pp. 535-549 (2007).

30. Sana, S.S. "A production-inventory model in an imperfect production process", Eur. J. Oper. Res., 200(2), pp. 451-464 (2010).

31. Sarkar, B., Sana, S.S., and Chaudhuri, K. "Optimal reliability, production lot size and safety stock in an imperfect production system", Int. J. Math. Oper. Res., 2(4), pp. 467-490 (2010).

32. Sarkar, B., Sana, S.S., and Chaudhuri, K. "An economic production quantity model with stochastic demand in an imperfect production system", Int. J. Serv. Oper. Manag., 9(3), pp. 259-283 (2011).

33. Dey, O. and Giri, B.C. "Optimal vendor investment for reducing defect rate in a vendor-buyer integrated system with imperfect production process", Int. J. Prod. Econ., 155, pp. 222-228 (2014).

34. Chiu, S.W. "Production lot size problem with failure in repair and backlogging derived without derivatives", Eur. J. Oper. Res., 188(2), pp. 610-615 (2008).

35. Lin, T.Y. "Optimal policy for a simple supply chain system with defective items and returned cost under screening errors", J. Oper. Res. Soc. Jpn., 52(3), pp. 307-320 (2009).

36. Yoo, S.H., Kim, D., and Park, M.S. "Economic production quantity model with imperfect-quality items, two-way imperfect inspection and sales return", Int. J. Prod. Econ., 121(1), pp. 255-265 (2009).

37. Hsu, J.T. and Hsu, L.F. "Two EPQ models with imperfect production processes, inspection errors, planned backorders, and sales returns", Comput. Ind. Eng., 64(1), pp. 389-402 (2013).

38. Wee, H.M., Wang, W.T., and Yang, P.C. "A production quantity model for imperfect quality items with shortage and screening constraint", Int. J. Prod. Res., 51(6), pp. 1869-1884 (2013).

39. Cárdenas-Barrón, L.E., Chung, K.J., and TreviñoGarza, G. "Celebrating a century of the economic order quantity model in honor of Ford Whitman Harris", Int. J. Prod. Econ., 155, pp. 1-7 (2014).

40. Taleizadeh, A.A., Khanbaglo, M.P.S., and CárdenasBarrón, L.E. "An EOQ inventory model with partial backordering and reparation of imperfect products", Int. J. Prod. Econ., 182, pp. 418-434 (2016).

41. Wang, W.T., Wee, H.M. Cheng, Y.L., Wen, C.L., and Cárdenas-Barrón, L.E. "EOQ model for imperfect quality items with partial backorders and screening constraint", Eur. J. Ind. Eng., 9(6), pp. 744-773 (2015).
42. Jaggi, C.K., Khanna, A., and Kishore, A. "Production inventory policies for defective items with inspection errors, sales return, imperfect rework process and backorders", In K. Singh, M. Pandey, L. Solanki, S. B. Dandin, \& P. S. Bhatnagar (Eds.), AIP Conf. Proc., 1715(1), p. 020062 (2016).

43. Moussawi-Haidar, L., Salameh, M., and Nasr, W. "Production lot sizing with quality screening and rework", Appl. Math. Model., 40(4), pp. 3242-3256 (2016).

44. Liao, G.L. "Production and maintenance policies for an EPQ model with perfect repair, rework, free-repair warranty, and preventive maintenance", IEEE T. Syst. Man CY.-S., 46(8), pp. 1129-1139 (2016).

45. Pal, S., Mahapatra, G.S., and Samanta, G.P. "A threelayer supply chain EPQ model for price-and stockdependent stochastic demand with imperfect item under rework", J. Uncert. Anal. Appl., 4(1), p. 10 (2016).

46. Shah, N.H., Patel, D.G., and Shah, D.B. "EPQ model for returned/reworked inventories during imperfect production process under price-sensitive stockdependent demand", Oper. Res., 18(2), pp. 1-17 (2016).

47. Sekar, T. and Uthayakumar, R. "A multi-production inventory model for deteriorating items considering penalty and environmental pollution cost with failure rework", Uncert. Sup. Chain Manag., 5(3), pp. 229242 (2017).

48. Benkherouf, L., Skouri, K., and Konstantaras, I. "Optimal batch production with rework process for products with time-varying demand over finite planning horizon", Oper. Res. Eng. Cyb. Sec., 113, pp. 57-68 (2017).

49. Chen, T.H. "Optimizing pricing, replenishment and rework decision for imperfect and deteriorating items in a manufacturer-retailer channel", Int. J. Prod. Econ., 183, pp. 539-550 (2017).

50. Shafiee-Gol, S., Nasiri, M.M., and Taleizadeh, A.A. "Pricing and production decisions in multi-product single machine manufacturing system with discrete delivery and rework", Opsearch, 53(4), pp. 873-888 (2016).

51. Jawla, P. and Singh, S. "Multi-item economic production quantity model for imperfect items with multiple production setups and rework under the effect of preservation technology and learning environment", Int. J. Ind. Eng. Comput., 7(4), pp. 703-716 (2016).

52. Cárdenas-Barrón, L.E., Treviño-Garza, G., Taleizadeh, A.A., and Vasant, P. "Determining replenishment lot size and shipment policy for an EPQ inventory model with delivery and rework", Math. Prob. Eng., 2015 (2015). 
53. Nobil, A.H., Sedigh, A.H.A., and Cárdenas-Barrón, L.E. "Multi-machine economic production quantity for items with scrapped and rework with shortages and allocation decisions", Scient. Iran., Transactions E, 25(4), pp. 2331-2346 (2018).

54. Chung, K.J., Ting, P.S., and Cárdenas-Barrón, L.E. "A simple solution procedure to solve the multidelivery policy into economic production lot size problem with partial rework", Scient. Iran., Transactions E, 24(5), pp. 2640-2644 (2017).

55. Nobil, A.H., Afshar Sedigh, A.H., Tiwari, S., and Wee, H.M. "An imperfect multi-item single machine production system with shortage, rework, and scrapped considering inspection, dissimilar deficiency levels, and non-zero setup times", Scient Iran, 26(1), pp. 557-570 (2019).

56. Adler, G.L. and Nanda, R. "The effects of learning on optimal lot size determination multiple product case", AIIE T., 6(1), pp. 21-27 (1974).

57. Sule, D.R. "A note on production time variation in determining EMQ under influence of learning and forgetting", AIIE T., 13(1), pp. 91-95 (1981).

58. Urban, T.L. "Analysis of production systems when run length influences product quality", Int. J. Prod. Res., 36(11), pp. 3085-3094 (1998).

59. Jaber, M.Y. and Bonney, M. "The economic manufacture/order quantity (EMQ/EOQ) and the learning curve: past, present, and future", Int. J. Prod. Econ., 59(1), pp. 93-102 (1999).

60. Jaber, M.Y. and Bonney, M. "Lot sizing with learning and forgetting in set-ups and in product quality", Int. J. Prod. Econ., 83(1), pp. 95-111 (2003).

61. Jaber, M.Y. "Lot sizing for an imperfect production process with quality corrective interruptions and improvements, and reduction in setups", Comput. Ind. Eng., 51(4), pp. 781-790 (2006).

62. Darwish, M.A. "EPQ models with varying setup cost", Int. J. Prod. Econ., 113(1), pp. 297-306 (2008).

63. Khan, M., Jaber, M.Y., Guiffrida, A.L., and Zolfaghari, S. "A review of the extensions of a modified EOQ model for imperfect quality items", Int. J. Prod. Econ., 132(1), pp. 1-12 (2011).

64. Konstantaras, I., Skouri, K., and Jaber, M.Y. "Inventory models for imperfect quality items with shortages and learning in inspection", Appl. Math. Model., 36(11), pp. 5334-5343 (2012).

65. Mukhopadhyay, A. and Goswami, A. "Economic Production Quantity (EPQ) model for three type imperfect items with rework and learning in setup", An Int. J. Optim. Control: Th. Appl. (IJOCTA), 4(1), pp. 5765 (2013).
66. Gautam, P. and Khanna, A. "An imperfect production inventory model with setup cost reduction and carbon emission for an integrated supply chain", Uncert. Sup. Chain Manag, 6(3), pp. 271-286 (2018).

\section{Appendix A}

The following section presents various mathematical expressions used in the model:

$$
\begin{aligned}
& p_{1}=\alpha(1-r) \text {, } \\
& p_{2}=\alpha r, \\
& p_{3}=(1-\alpha) q_{1}, \\
& G_{1}=s(1-\alpha)+s \alpha r+v \alpha(1-r)-C_{p} \\
& -d_{1}\left(\frac{\lambda}{\phi(1-\alpha)}\right)-d_{2} \frac{(\phi-\lambda)}{\phi} \\
& -d_{3}\left[\alpha+(1-\alpha) q_{1}\right]-C_{w} \alpha r-C_{r}(1-\alpha) q_{1} \\
& -C_{a} \alpha q_{2}-u \alpha(1-r), \\
& G_{2}=-d_{2}\left\{\frac{\left[\phi-\left(1-p_{1}\right) x\right]}{\left(1-p_{1}\right) x-\lambda}-\frac{(\phi-\lambda)}{\left(1-p_{1}\right) x-\lambda}\right\}, \\
& G_{3}=-\frac{h}{2} \frac{(\phi-\lambda)}{\phi^{2}}+\frac{h p_{1}}{2}\left(\frac{1}{x}-\frac{1}{\phi}\right)+\frac{h \lambda}{2}\left(\frac{1}{x}-\frac{1}{\phi}\right)^{2} \\
& -\frac{h}{\phi}\left(\frac{1}{x}-\frac{1}{\phi}\right)(\phi-\lambda)-\frac{h}{2 \lambda}\left\{\frac{(\phi-\lambda)}{\phi}\right. \\
& \left.-\lambda\left(\frac{1}{x}-\frac{1}{\phi}\right)-p_{1}-\frac{p_{2}\left(\phi_{1}-\lambda\right)}{\phi_{1}}\right\}^{2} \\
& -\frac{h}{2 \lambda} \alpha q_{2}\left(1-p_{1}\right) y^{2}-\frac{h_{1}}{2}\left\{2 \left\{\frac{(\phi-\lambda)}{\phi}\right.\right. \\
& \left.\left.-\lambda\left(\frac{1}{x}-\frac{1}{\phi}\right)-p_{1}\right\}-\frac{p_{2}\left(\phi_{1}-\lambda\right)}{\phi_{1}}\right\}\left(\frac{p_{2}}{\phi_{1}}\right), \\
& G_{4}=\frac{h}{2} \frac{\left[\phi-\left(1-p_{1}\right) x\right]}{\left[\left(1-p_{1}\right) x-\lambda\right]^{2}}+h\left[\frac{\left[\phi-\left(1-p_{1}\right) x\right]}{\left[\left(1-p_{1}\right) x-\lambda\right]^{2}}\right] \\
& -\frac{h}{2} \frac{(\phi-\lambda)}{\left[\left(1-p_{1}\right) x-\lambda\right]^{2}}-\frac{h}{2 \lambda}\left\{\frac{\left[\phi-\left(1-p_{1}\right) x\right]}{\left(1-p_{1}\right) x-\lambda}\right. \\
& \left.+\frac{(\phi-\lambda)}{\left(1-p_{1}\right) x-\lambda}\right\}^{2} \\
& +C_{B} \frac{1}{2}\left(\frac{1}{\lambda}+\frac{1}{\left(1-p_{1}\right) x-\lambda}\right),
\end{aligned}
$$




$$
\begin{aligned}
G_{5}= & \frac{d_{2} \lambda}{\phi(1-\lambda)}-\frac{h}{\phi}\left[\frac{\left[\phi-\left(1-p_{1}\right) x\right]}{\left(1-p_{1}\right) x-\lambda}\right] \\
& +h \frac{(\phi-\lambda)}{2 \phi} \frac{1}{\left(1-p_{1}\right) x-\lambda}-h\left(\frac{1}{x}-\frac{1}{\phi}\right) \\
& \left\{\frac{\left[\phi-\left(1-p_{1}\right) x\right]}{\left(1-p_{1}\right) x-\lambda}-\frac{(\phi-\lambda)}{\left(1-p_{1}\right) x-\lambda}\right\} \\
& -\frac{h}{2 \lambda}\left\{\frac{\left[\phi-\left(1-p_{1}\right) x\right]}{\left(1-p_{1}\right) x-\lambda}-\frac{(\phi-\lambda)}{\left(1-p_{1}\right) x-\lambda}\right\} \\
& \left\{\frac{(\phi-\lambda)}{\phi}-\lambda\left(\frac{1}{x}-\frac{1}{\phi}\right)-p_{1}-\frac{p_{2}\left(\phi_{1}-\lambda\right)}{\phi_{1}}\right\} \\
& -h_{1}\left\{\frac{\left[\phi-\left(1-p_{1}\right) x\right]}{\left(1-p_{1}\right) x-\lambda}-\frac{(\phi-\lambda)}{\left(1-p_{1}\right) x-\lambda}\right\} \\
& \left(\frac{p_{2}}{\phi_{1}}\right) \cdot
\end{aligned}
$$

\section{Appendix B}

The following section represents the expected value of the mathematical expressions used in the model:

$$
\begin{aligned}
& E\left[p_{1}\right]=E[\alpha](1-E[r]), \\
& E\left[p_{2}\right]=E[\alpha] E[r], \\
& E\left[p_{3}\right]=(1-E[\alpha]) E\left[q_{1}\right], \\
& E\left[G_{1}\right]=s(1-E[\alpha])+s E[\alpha] E[r] \\
& +v E[\alpha](1-E[r])-C_{p} \\
& -d_{1}\left(\frac{\lambda}{\phi(1-E[\alpha])}\right)-d_{2} \frac{(\phi-\lambda)}{\phi} \\
& -d_{3}\left\{E[\alpha]+(1-E[\alpha]) E\left[q_{1}\right]\right\} \\
& -C_{w} E[\alpha] E[r]-C_{r}(1-E[\alpha]) E\left[q_{1}\right] \\
& -C_{a} E[\alpha] E\left[q_{2}\right]-u E[\alpha](1-E[r]), \\
& E\left[G_{2}\right]=-d_{2}\left\{\frac{\left[\phi-\left(1-E\left[p_{1}\right]\right) x\right]}{\left(1-E\left[p_{1}\right]\right) x-\lambda}\right. \\
& \left.-\frac{(\phi-\lambda)}{\left(1-E\left[p_{1}\right]\right) x-\lambda}\right\} \\
& E\left[G_{3}\right]=-\frac{h}{2} \frac{(\phi-\lambda)}{\phi^{2}}+\frac{h E\left[p_{1}\right]}{2}\left(\frac{1}{x}-\frac{1}{\phi}\right) \\
& +\frac{h \lambda}{2}\left(\frac{1}{x}-\frac{1}{\phi}\right)^{2}-\frac{h}{\phi}\left(\frac{1}{x}-\frac{1}{\phi}\right)(\phi-\lambda)
\end{aligned}
$$

$-\frac{h}{2 \lambda}\left\{\frac{(\phi-\lambda)}{\phi}-\lambda\left(\frac{1}{x}-\frac{1}{\phi}\right)-E\left[p_{1}\right]\right.$

$\left.-\frac{E\left[p_{2}\right]\left(\phi_{1}-\lambda\right)}{\phi_{1}}\right\}^{2}-\frac{h}{2 \lambda} E[\alpha] E\left[q_{2}\right]$

$\left(1-E\left[p_{1}\right]\right) y^{2}-\frac{h_{1}}{2}\left\{2\left\{\frac{(\phi-\lambda)}{\phi}\right.\right.$

$\left.\left.-\lambda\left(\frac{1}{x}-\frac{1}{\phi}\right)-E\left[p_{1}\right]\right\}-\frac{E\left[p_{2}\right]\left(\phi_{1}-\lambda\right)}{\phi_{1}}\right\}$

$\left(\frac{E\left[p_{2}\right]}{\phi_{1}}\right)$

$$
\begin{aligned}
E\left[G_{4}\right] & =\frac{h}{2} \frac{\left[\phi-\left(1-E\left[p_{1}\right]\right) x\right]}{\left[\left(1-E\left[p_{1}\right]\right) x-\lambda\right]^{2}} \\
& +h\left[\frac{\left[\phi-\left(1-E\left[p_{1}\right]\right) x\right]}{\left[\left(1-E\left[p_{1}\right]\right) x-\lambda\right]^{2}}\right]
\end{aligned}
$$$$
-\frac{h}{2} \frac{(\phi-\lambda)}{\left[\left(1-E\left[p_{1}\right]\right) x-\lambda\right]^{2}}
$$$$
-\frac{h}{2 \lambda}\left\{\frac{\left[\phi-\left(1-E\left[p_{1}\right]\right) x\right]}{\left(1-E\left[p_{1}\right]\right) x-\lambda}+\frac{(\phi-\lambda)}{\left(1-E\left[p_{1}\right]\right) x-\lambda}\right\}^{2}
$$$$
+C_{B} \frac{1}{2}\left(\frac{1}{\lambda}+\frac{1}{\left(1-E\left[p_{1}\right]\right) x-\lambda}\right),
$$

$$
E\left[G_{5}\right]=\frac{d_{2} \lambda}{\phi(1-\lambda)}-\frac{h}{\phi}\left[\frac{\left[\phi-\left(1-E\left[p_{1}\right]\right) x\right]}{\left(1-E\left[p_{1}\right]\right) x-\lambda}\right]
$$$$
+h \frac{(\phi-\lambda)}{2 \phi} \frac{1}{\left(1-E\left[p_{1}\right]\right) x-\lambda}
$$$$
-h\left(\frac{1}{x}-\frac{1}{\phi}\right)\left\{\frac{\left[\phi-\left(1-E\left[p_{1}\right]\right) x\right]}{\left(1-E\left[p_{1}\right]\right) x-\lambda}\right.
$$

$$
\left.-\frac{(\phi-\lambda)}{\left(1-E\left[p_{1}\right]\right) x-\lambda}\right\}
$$$$
-\frac{h}{2 \lambda}\left\{\frac{\left[\phi-\left(1-E\left[p_{1}\right]\right) x\right]}{\left(1-E\left[p_{1}\right]\right) x-\lambda}\right.
$$$$
\left.-\frac{(\phi-\lambda)}{\left(1-E\left[p_{1}\right]\right) x-\lambda}\right\}\left\{\frac{(\phi-\lambda)}{\phi}\right.
$$$$
\left.-\lambda\left(\frac{1}{x}-\frac{1}{\phi}\right)-E\left[p_{1}\right]-\frac{E\left[p_{2}\right]\left(\phi_{1}-\lambda\right)}{\phi_{1}}\right\}
$$$$
-h_{1}\left\{\frac{\left[\phi-\left(1-E\left[p_{1}\right]\right) x\right]}{\left(1-E\left[p_{1}\right]\right) x-\lambda}\right.
$$$$
\left.-\frac{(\phi-\lambda)}{\left(1-E\left[p_{1}\right]\right) x-\lambda}\right\}\left(\frac{E\left[p_{2}\right]}{\phi_{1}}\right) \text {. }
$$ 


\section{Appendix C}

Case I: $T_{P}<T_{M}$.

C1: Proof of first condition of concavity is as follows:

$$
\frac{\partial^{2}}{\partial y^{2}} E\left[Z_{1}(y, B)\right] \leq 0
$$

i.e.:

$$
\begin{aligned}
\frac{\lambda}{1-\{E[\alpha](1-E[r])\}}\left\{-2 d_{2} \frac{B}{y^{3}}-2 h \frac{B^{2}}{y^{3}}\right. \\
\\
\quad \frac{\{\phi-\{1-\{E[\alpha](1-E[r])\}\} x\}}{\{\{1-\{E[\alpha](1-E[r])\}\} x-\lambda\}^{2}}-\left(C_{B}-h\right) \\
\frac{B^{2}}{y^{3}}\left(\frac{1}{\lambda}+\frac{1}{\{\{1-\{E[\alpha](1-E[r])\}\} x-\lambda\}}\right) \\
\left.-\frac{c_{0}(\in-1)(\in-2) y^{(\in-3)}}{\varphi^{\epsilon}}\right\} \leq 0 .
\end{aligned}
$$

Proof: As $0 \leq E[\alpha], E[r] \leq 1, \therefore$ the following inequalities hold true:

$$
(1-E[r]) \geq 0 \Rightarrow 1-\{E[\alpha](1-E[r])\} \geq 0 .
$$

As $0 \leq \in \leq 1, \therefore$ the following inequalities hold true:

$$
(\in-1) \leq 0 ;(\in-2) \leq 0 .
$$

Also, from model constraints (5) and (7), we have:

$$
\left[\phi-\left(1-E\left[p_{1}\right]\right) x\right] \geq 0 \text { and }\left[\left(1-E\left[p_{1}\right]\right) x-\lambda\right] \geq 0,
$$

i.e.:

$$
\begin{aligned}
& \phi-\{1-\{E[\alpha](1-E[r])\}\} x \geq 0 ; \\
& \{1-\{E[\alpha](1-E[r])\}\} x-\lambda \geq 0 .
\end{aligned}
$$

So, the first condition of concavity holds true under the condition of $C_{B} \geq h$.

C2: Proof of the second condition of concavity is as follows:

$$
\frac{\partial^{2}}{\partial B^{2}} E\left[Z_{1}(y, B)\right] \leq 0
$$

i.e.:

$$
\begin{aligned}
& \frac{2 \lambda B^{2}}{\{1-\{E[\alpha](1-E[r])\}\} y^{4}} \\
& \quad\left\{2 h \frac{[\phi-\{1-\{E[\alpha](1-E[r])\}\} x]}{\{\{1-\{E[\alpha](1-E[r])\}\} x-\lambda\}^{2}}+\left(C_{B}-h\right)\right. \\
& \left.\quad\left(\frac{1}{\lambda}+\frac{1}{\{\{1-\{E[\alpha](1-E[r])\}\} x-\lambda\}}\right)\right\} \leq 0 .
\end{aligned}
$$

Proof: As $0 \leq E[\alpha], E[r] \leq 1, \therefore$ the following inequalities hold true:

$$
(1-E[r]) \geq 0 \Rightarrow 1-\{E[\alpha](1-E[r])\} \geq 0 .
$$

Also, from model constraints (5) and (7), we have:

$$
\left[\phi-\left(1-E\left[p_{1}\right]\right) x\right] \geq 0 \text { and }\left[\left(1-E\left[p_{1}\right]\right) x-\lambda\right] \geq 0 .
$$
i.e.:

$$
\begin{aligned}
& \phi-\{1-\{E[\alpha](1-E[r])\}\} x \geq 0 \\
& \{1-\{E[\alpha](1-E[r])\}\} x-\lambda \geq 0 .
\end{aligned}
$$

So, the second condition of concavity holds true under the condition of the relation shown in Box C.I.

C3: Proof of the third condition of concavity is as follows:

$$
\begin{gathered}
\left(\frac{\partial^{2}}{\partial y \partial B} E\left[Z_{1}(y, B)\right]\right)^{2}-\left(\frac{\partial^{2}}{\partial y^{2}} E\left[Z_{1}(y, B)\right]\right) \\
\left(\frac{\partial^{2}}{\partial B^{2}} E\left[Z_{1}(y, B)\right]\right) \leq 0
\end{gathered}
$$

i.e.:

$$
\begin{aligned}
& \left(\frac{\lambda}{y^{2}\{1-\{E[\alpha](1-E[r])\}\}}\right)^{2} \\
& \quad\left\{d_{2}{ }^{2}+\frac{2 c_{0}(\in-1)(\epsilon-2) y^{\in} B^{2}}{y^{3} \varphi^{\epsilon}}\right. \\
& \quad\left\{2 h \frac{[\phi-\{1-\{E[\alpha](1-E[r])\}\} x]}{[\{1-\{E[\alpha](1-E[r])\}\} x-\lambda]^{2}}+\left(C_{B}-h\right)\right. \\
& \left.\left.\quad\left(\frac{1}{\lambda}+\frac{1}{\{1-\{E[\alpha](1-E[r])\}\} x-\lambda}\right)\right\}\right\} \leq 0 .
\end{aligned}
$$

Proof: As $0 \leq E[\alpha], E[r] \leq 1, \therefore$ the following inequalities hold true:

$$
\frac{C_{B}}{h} \leq\left(1-\frac{2 \lambda[\phi-\{1-\{E[\alpha](1-E[r])\}\} x]}{\{1-\{E[\alpha](1-E[r])\}\} x[\{1-\{E[\alpha](1-E[r])\}\} x-\lambda]}\right) .
$$




$$
(1-E[r]) \geq 0 \Rightarrow 1-\{E[\alpha](1-E[r])\} \geq 0 .
$$

As $0 \leq \epsilon \leq 1, \therefore$ the following inequalities hold true:

$$
(\in-1) \leq 0 ; \quad(\in-2) \leq 0 .
$$

Also, from model constraints (5) and (7), we have:

$$
\left[\phi-\left(1-E\left[p_{1}\right]\right) x\right] \geq 0 \text { and }\left[\left(1-E\left[p_{1}\right]\right) x-\lambda\right] \geq 0,
$$

i.e.:

$$
\begin{aligned}
& \phi-\{1-\{E[\alpha](1-E[r])\}\} x \geq 0 ; \\
& \{1-\{E[\alpha](1-E[r])\}\} x-\lambda \geq 0 .
\end{aligned}
$$

So, the third condition of concavity holds true under the condition of:

$$
\begin{aligned}
\left(\frac{d_{2}}{B}\right)^{2} & \leq \frac{2 c_{0}(\in-1)(\epsilon-2) y^{\epsilon}}{y^{3} \varphi^{\epsilon}}\left\{( h - C _ { B } ) \left(\frac{1}{\lambda}\right.\right. \\
& \left.+\frac{1}{\{1-\{E[\alpha](1-E[r])\}\} x-\lambda}\right) \\
& \left.-2 h \frac{[\phi-\{1-\{E[\alpha](1-E[r])\}\} x]}{[\{1-\{E[\alpha](1-E[r])\}\} x-\lambda]^{2}}\right\} .
\end{aligned}
$$

Hence, the global concavity of the objective function for Case I has been proved mathematically.

\section{Appendix D}

Case II: $T_{M} \geq T_{P}$

D1: Proof of the first condition of concavity is as follows:

$$
\frac{\partial^{2}}{\partial y^{2}} E\left[Z_{1}(y, B)\right] \leq 0
$$

i.e.:

$$
\begin{aligned}
& \frac{\lambda}{1-\{E[\alpha](1-E[r])\}}\left\{-2 d_{2} \frac{B}{y^{3}}-2 h \frac{B^{2}}{y^{3}}\right. \\
& \frac{\{\phi-\{1-\{E[\alpha](1-E[r])\}\} x\}}{\{\{1-\{E[\alpha](1-E[r])\}\} x-\lambda\}^{2}}-\left(C_{B}-h\right) \\
& \frac{B^{2}}{y^{3}}\left(\frac{1}{\lambda}+\frac{1}{\{\{1-\{E[\alpha](1-E[r])\}\} x-\lambda\}}\right) \\
& \left.-\frac{2 C_{\max }}{y^{3}}\right\} \leq 0 .
\end{aligned}
$$

Proof: As $0 \leq E[\alpha], E[r] \leq 1, \therefore$ the following inequalities hold true:

$$
(1-E[r]) \geq 0 \Rightarrow 1-\{E[\alpha](1-E[r])\} \geq 0 .
$$

Also, from model constraints (5) and (7), we have:

$$
\left[\phi-\left(1-E\left[p_{1}\right]\right) x\right] \geq 0 \text { and }\left[\left(1-E\left[p_{1}\right]\right) x-\lambda\right] \geq 0,
$$
i.e.:

$$
\begin{aligned}
& \phi-\{1-\{E[\alpha](1-E[r])\}\} x \geq 0 \\
& \{1-\{E[\alpha](1-E[r])\}\} x-\lambda \geq 0 .
\end{aligned}
$$

So, the first condition of concavity holds true under the condition of $C_{B} \geq h$.

D2: Proof of the second condition of concavity is as follows:

$$
\frac{\partial^{2}}{\partial B^{2}} E\left[Z_{1}(y, B)\right] \leq 0,
$$

i.e.:

$$
\begin{aligned}
&\left.\frac{2 \lambda B^{2}}{\{1-}\{E[\alpha](1-E[r])\}\right\} y^{4} \\
&\left\{2 h \frac{[\phi-\{1-\{E[\alpha](1-E[r])\}\} x]}{\{\{1-\{E[\alpha](1-E[r])\}\} x-\lambda\}^{2}}+\left(C_{B}-h\right)\right. \\
&\left.\left(\frac{1}{\lambda}+\frac{1}{\{\{1-\{E[\alpha](1-E[r])\}\} x-\lambda\}}\right)\right\} \leq 0 .
\end{aligned}
$$

Proof: As $0 \leq E[\alpha], E[r] \leq 1, \therefore$ the following inequalities hold true:

$$
(1-E[r]) \geq 0 \Rightarrow 1-\{E[\alpha](1-E[r])\} \geq 0 .
$$

Also, from model constraints (5) and (7), we have:

$$
\begin{aligned}
& {\left[\phi-\left(1-E\left[p_{1}\right]\right) x\right] \geq 0 \text { and }\left[\left(1-E\left[p_{1}\right]\right) x-\lambda\right] \geq 0} \\
& \phi-\{1-\{E[\alpha](1-E[r])\}\} x \geq 0 \\
& \{1-\{E[\alpha](1-E[r])\}\} x-\lambda \geq 0
\end{aligned}
$$
i.e.:

So, the second condition of concavity holds true under the condition of the relation shown in Box D.I.:

D3: Proof of the third condition of concavity is as follows:

$$
\frac{C_{B}}{h} \leq\left(1-\frac{2 \lambda[\phi-\{1-\{E[\alpha](1-E[r])\}\} x]}{\{1-\{E[\alpha](1-E[r])\}\} x[\{1-\{E[\alpha](1-E[r])\}\} x-\lambda]}\right)
$$




$$
\begin{gathered}
\left(\frac{\partial^{2}}{\partial y \partial B} E\left[Z_{1}(y, B)\right]\right)^{2}-\left(\frac{\partial^{2}}{\partial y^{2}} E\left[Z_{1}(y, B)\right]\right) \\
\left(\frac{\partial^{2}}{\partial B^{2}} E\left[Z_{1}(y, B)\right]\right) \leq 0,
\end{gathered}
$$

i.e.:

$$
\begin{gathered}
\left(\frac{\lambda}{y^{2}\{1-\{E[\alpha](1-E[r])\}\}}\right)^{2} *\left\{d_{2}{ }^{2}+4 C_{\max } \frac{B^{2}}{y^{3}}\right. \\
\left\{2 h \frac{[\phi-\{1-\{E[\alpha](1-E[r])\}\} x]}{[\{1-\{E[\alpha](1-E[r])\}\} x-\lambda]^{2}}+\left(C_{B}-h\right)\right. \\
\left.\left.\left(\frac{1}{\lambda}+\frac{1}{\{1-\{E[\alpha](1-E[r])\}\} x-\lambda}\right)\right\}\right\} \leq 0 .
\end{gathered}
$$

Proof: As $0 \leq E[\alpha], E[r] \leq 1, \therefore$ the following inequalities hold true:

$$
(1-E[r]) \geq 0 \Rightarrow 1-\{E[\alpha](1-E[r])\} \geq 0 .
$$

Also, from model constraints (5) and (7), we have:

$$
\left[\phi-\left(1-E\left[p_{1}\right]\right) x\right] \geq 0 \text { and }\left[\left(1-E\left[p_{1}\right]\right) x-\lambda\right] \geq 0,
$$

i.e.:

$$
\begin{aligned}
& \phi-\{1-\{E[\alpha](1-E[r])\}\} x \geq 0 ; \\
& \{1-\{E[\alpha](1-E[r])\}\} x-\lambda \geq 0 .
\end{aligned}
$$

So, the third condition of concavity holds true under the condition of:

$$
\begin{aligned}
\left(\frac{d_{2}}{B}\right)^{2} & \leq \frac{4 C_{\max }}{y^{3}}\left\{( h - C _ { B } ) \left(\frac{1}{\lambda}\right.\right. \\
& \left.+\frac{1}{\{1-\{E[\alpha](1-E[r])\}\} x-\lambda}\right) \\
& \left.-2 h \frac{[\phi-\{1-\{E[\alpha](1-E[r])\}\} x]}{[\{1-\{E[\alpha](1-E[r])\}\} x-\lambda]^{2}}\right\} .
\end{aligned}
$$

Hence, the global concavity of the objective function for Case II has been proved mathematically.

\section{Biographies}

Aakanksha Kishore is a research scholar in the Department of Operational Research, University of Delhi, India. She received her MSc degree in Operational Research in 2012 from the University of Delhi, India. Her research interest includes inventory management. She published six research papers in IJIEC, RAIRO Operations Research, Mathematics, IJMEMS, Control \& Cybernetics, and AIP proceeding.

Prerna Gautam is a research scholar in the Department of Operational Research, University of Delhi, India. She received her MPhil in Inventory Management in 2015 and MSc degree in Operational Research in 2013 from the University of Delhi, India. She has three book chapters and five research papers published in DSL, USCM, IJMEMS, RAIRO Operations Research, and AIP proceeding. Her research interest includes inventory and supply chain management.

Aditi Khanna is currently an Assistant Professor in the Department of Operational Research, University of Delhi, India. She received her $\mathrm{PhD}$ degree in Inventory Management in 2010, MPhil in Inventory Management in 2004, and MSc in Operational Research in 2002 from the University of Delhi, India. She has numerous research papers published in various international journals including IJPE, AMM, IJSS, IJIEC, DSL, YUJOR, Control \& Cybernetics, IJSOI, IJADS, IJPM, IJOR, IJMOR, IJSDS, CJPAS, and OPSEARCH.

Chandra K. Jaggi is a Professor in the Department of Operational Research, University of Delhi, India. His research interest include supply chain and inventory management. He has published seven book chapters and more than 115 papers in various international/national journals including IJPE, EJOR, CAIE, JORS, AMM, AMC, AMIS, IJSS, TOP, IJOR, IJADS, IJSDS, DSL, YUJOR, etc. He is a reviewer of more than 25 international/national journals. He has guided $10 \mathrm{PhD}$ and $20 \mathrm{MPhil}$ students in Operations Research. He is the Ex-Editor-in-Chief of IJICM, associate editor of IJSAEM, Springer, and an editorial board member of the IJSS: Operations \& Logistics, IJSOI, AJOR, IJECBS, JASR, and AJBAS. 